SEASONAL CYCLES, BUSINESS CYCLES, AND MONETARY POLICY

by

Zheng Liu

Discussion Paper No. 292, November 1996

\author{
Center for Economic Research \\ Department of Economics \\ University of Minnesota \\ Minneapolis, MN 55455
}




\title{
Seasonal Cycles, Business Cycles, and Monetary Policy
}

\author{
Zheng Liu ${ }^{1}$ \\ University of Minnesota \\ Department of Economics
}

November 18, 1996

\begin{abstract}
Empirical studies show that the Federal Reserve System (Fed) has been smoothing short-term nominal interest rates across seasonal cycles, but has allowed interest rates to co-move with output over business cycles, despite striking similarities between the two cycles in terms of output co-movements and relative volatilities. This paper tries to explain why the Fed has been treating the two cycles so differently. To address this issue, I first construct a monetary growth model which replicates the seasonal and cyclical patterns of aggregate U.S. data. Then I use the model to compare the historical U.S. monetary policy with two alternative policy rules, namely the constant-interestrate rule proposed by Carlstrom and Fuerst (1996), and the constant-money-growth rule advocated by Friedman $(1959,1982)$. Both alternatives are constrained to generate the same seigniorage revenue as the historical policy. Numerical simulations show that (1)the model captures both the real and nominal features of U.S. data quite well and it outperforms traditional cash-in-advance models in replicating the nominal variables; and (2) the historical monetary policy attains higher welfare than both alternatives. It is demonstrated that the model's success on the nominal side is attributable to the assumption of consumption durability and the introduction of a shock to the transaction technology. It is argued that the findings from the welfare experiments extend Poole's (1970) insights to a dynamic and stochastic environment, and that these findings suggest that the Fed has been sensibly choosing its monetary policy in response to seasonal swings and business cycle fluctuations, rather than creating exogenous disturbances to the economy.
\end{abstract}

\footnotetext{
${ }^{1}$ This paper is a chapter of my dissertation. I thank R. Anton Braun and Lee Ohanian for their advice and encouragement throughout this research. Special thanks to my advisor Nobuhiro Kiyotaki who has offered invaluable advice, guidance, and help. Helpful comments from Edward C. Prescott, Warren Weber, and Edward Green are appreciated. The author is fully responsible for all remaining errors.

Correspondence: Department of Economics, University of Minnesota, 1035 Management and Economics, 271 19th Avenue South, Minneapolis, MN 55455. E-mail: zliu@atlas.socsci.umn.edu
} 


\section{Introduction}

This paper analyzes the choice of monetary policy in response to seasonal swings and business cycle fluctuations in the U.S. economy. Recent empirical studies show that there is a regular seasonal cycle in addition to the business cycle, and that the two cycles are very similar in many aspects. Over both cycles, outputs co-move across sectors. At the same time, prices are much less variable than quantities (Barsky and Miron, 1989). However, there is substantial evidence suggesting that the Federal Reserve System (Fed) has been treating the two cycles quite differently. Historically, the monetary authority has been accommodating seasonal swings of economic activities by adjusting money supply. During seasons when money demand increases, the Fed expands the money stock to prevent nominal interest rates from rising. As a consequence, short-term nominal interest rates are smoothed across seasons ${ }^{2}$. In contrast, over business cycles, the Fed tends to raise short-term nominal interest rates during booms in order to curb inflation, and lower interest rates when recession is anticipated. Consequently, nominal interest rates are procyclical. ${ }^{3}$. These observations merit the question of whether there are sound economic reasons for the Fed to treat the two cycles so differently.

In order to address this issue, I first construct a theoretical framework which explains seasonal and business cycle phenomena in the U.S. economy. The real side of the economy is a standard real business cycle model as in Kydland and Prescott (1982). In order to generate seasonal predictions, I introduce deterministic seasonal components in consumer preferences and technologies in the model ${ }^{4}$. The monetary part of the model is a variant of Aiyagari, Braun, and Eckstein (1995). It features explicit credit service production and endogenous distinctions between cash goods and credit goods. Since traditional cash-in-advance models such as Cooley and Hansen $(1989,1995)$ counterfactually predict large variations of nominal variables at both the seasonal and business cycle frequencies, I modify the traditional model in two important aspects in order to improve the model's nominal predictions. First, I assume that consumption exhibits local durability (Dunn and Singleton, 1986). That is, a typical consumer derives utility from consumption purchases of both current and previous

\footnotetext{
${ }^{2}$ Barsky and Miron (1989), Barro (1989), Mankiw and Miron (1991), and Miron (1986) have found substantial evidence of seasonal interest rate smoothing policy since the founding of the Federal Reserve System.

${ }^{3}$ See Cooley and Hansen (1995), Chari, Christiano, and Eichenbaum (1994), and Cagan (1971).

${ }^{4} \mathrm{I}$ follow the same approach to introducing seasonality as in Christiano and Todd (1995), Braun and Evans (1991, 1994), and Chatterjee and Ravikumar (1992).
} 
periods. This aspect of the model effectively increases the intertemporal elasticity of substitution in consumption, and thus reduces the variability in real interest rates. Second, I introduce a transaction technology shock which captures the residual movement between velocity and nominal interest rate in the money demand equation. The transaction technology shock serves as a buffer in the sense that it allows money velocity to fluctuate in response to shocks, while it offsets the effects of exogenous shocks and seasonal shifts on nominal interest rates. Therefore the consumption durability and transaction technology shock jointly produce dampened variations in both real and nominal interest rates. As a consequence, fluctuations in nominal prices are smoothed.

Given the empirical success of the theoretical framework, I use the model to conduct several welfare experiments. Specifically, the historical U.S. monetary policy which smooths nominal interest rates across seasons but allows interest rates to be procyclical is compared with two distinct alternative policy rules. The first is the constant-interest-rate rule proposed by Carlstrom and Fuerst (1996), and the other is the constant-money-growth rule advocated by Friedman $(1959,1982)$. Each alternative is constrained to generate the same seigniorage revenue as the historical policy. I find that historical monetary policy yields higher social welfare than either alternative. This result is consistent with Poole's (1970) insights. Poole uses an IS-LM framework and suggests that if shocks are primarily in the demand for money, smoothing interest rates is desirable; if they originate in the goods market, interest rates should be allowed to co-move with output because the interest rate movement would partially offset output fluctuations. In my model, the transaction technology shock acts like a money demand shock, and it is more important over the seasons. Thus seasonal interest rate smoothing is desirable. However, over business cycles, the effects of the more persistent technology shocks build up while the less persistent transaction technology shocks average out. Therefore allowing nominal interest rates to be procyclical is a sensible policy.

- My work adds to the study of economic fluctuations and monetary policy in two aspects. First, in a positive sense, it is an attempt to integrate the studies of business cycle fluctuations with seasonal swings of the economy ${ }^{5}$. Traditionally, many researchers treat seasonal components of economic time series as "errors in variables" which should be removed before the time series is used (Sims, 1974). However, recent empirical work such as Barsky

\footnotetext{
${ }^{5}$ Among others, the work by Singleton (1988), Barsky and Miron (1989), Braun and Evans (1994), Chatterjee and Ravikumar(1992), and Miron (1996) represents efforts to integrate the studies of business cycle with seasonal cycle.
} 
and Miron (1989) and Miron (1996) points out that seasonal fluctuations are important and studying them would help economists better understand business cycles. My work supports the latter view: it demonstrates that although the sources of shocks across the seasonal cycle and the business cycle can be very different, the propagation mechanisms can be similar.

Secondly, in a normative sense, my work extends Poole's (1970) insights about the choice of monetary policy to a dynamic and stochastic environment. The findings from the welfare experiments suggest that the Fed has been sensibly choosing monetary policy in response to seasonal swings and business cycle fluctuations, rather than creating exogenous disturbances to the economy. This research adds to other recent work that has revived the interest in evaluating welfare consequences of alternative monetary policies. Recent work by Carlstrom and Fuerst (1995) focuses on welfare implications of the money growth rule versus the interest rule in an economy with cash-in-advance constraints, limited participation, and portfolio rigidity. They find that the interest rate rule is better than the money growth rule over the business cycles in terms of social welfare, because smoothing interest rates would provide more flexibility for firms and households to respond to shocks. In an IS-LM framework, Mankiw and Miron (1991) find that the welfare cost is lower if nominal interest rates are smoothed over seasons. Chatterjee (1993) studies implications of the interest rate smoothing policy in a deterministic cash-in-advance economy, and finds that smoothing interest rates is welfare improving. Other authors such as Miron (1986) and Canova (1991) have investigated the role of the seasonal interest rate smoothing policy in eliminating bank runs and financial panics at the time when the Fed was established. However, little work has been done to quantify the welfare effects of alternative monetary policies based on models which can explain both the seasonal and business cycle facts of the U.S. economy. Therefore, my work is a complement to this area.

The paper is organized as follows. Section 2 lays out the model and computation methods; section 3 describes the data and the choice of parameter values; section 4 discusses the firstmoment and second-moment properties of the model and compares them to those of the U.S. economy; and section 5 outlines the policy experiments. Finally, section 6 concludes the paper. 


\section{The Model}

The economy consists of a government, a large number of identical firms and a large number of identical households, all of whom are infinitely-lived. So the discussions will be restricted to a representative agent of each type. I first describe the optimization decisions for the representative firm and household, taking government policy as exogenously given, then characterize the equilibrium behavior.

\subsection{The Environment}

There are two intermediate goods production sectors which use the primary factors capital and labor as inputs. A third sector produces final goods with the only inputs being intermediate goods. All technologies exhibit constant returns to scale, and all individual producers in each sector maximize profits taking prices of output and inputs as given.

The production technology of the intermediate goods sector is

$$
X_{j t}=F\left(K_{j t}, A_{t} N_{j t}\right), \quad j=1,2,
$$

where $X_{j t}$ is the output of intermediate goods $j \in\{1,2\}, K_{j t}$ and $N_{j t}$ are the quantities of capital and labor input in sector $j$, and $A_{t}$ is a labor augmenting technology shock which follows a trend stationary stochastic process and which includes deterministic seasonal components:

$$
\begin{gathered}
A_{t}=A_{t-1} \exp \left(\lambda_{t}\right) . \\
\lambda_{t}=\lambda_{t}^{d}+\tilde{\lambda}_{t},
\end{gathered}
$$

where $\lambda_{t}^{d}=\sum_{s=1}^{4} \lambda_{s} D_{s t}, D_{s t}$ is a seasonal dummy which equals one if period $t$ corresponds to season $s$, otherwise it is zero. $\tilde{\lambda}_{t}$ is the stochastic component of $\lambda_{t}{ }^{6}$.

- It is assumed that the output of the first sector $X_{1 t}$ is uniformly distributed across a continuum of types indexed by $z \in[0,1]$. The output of the second sector $X_{2 t}$ is interpreted as "credit services" as in Aiyagari, et. al. (1995).

There are two types of final goods production technologies. One unit of type $z$ intermediate goods $X_{1 t}(z)$ can either be transformed into one unit of cash goods $Y_{1 t}(z)$ (on a

\footnotetext{
${ }^{6}$ This way of decomposing a stochastic variable into a deterministic seasonal component and a stochastic component is suggested by Barsky and Miron (1989), and it is particularly easy to be fitted into standard business cycle models.
} 
one-to-one basis), or it can be combined with $S\left(z, q_{t}\right)$ units of credit services to produce one unit of type $z$ credit goods $Y_{2 t}(z)$. Specifically, the production technology for cash goods is

$$
Y_{1 t}(z)=X_{1 t}(z)
$$

and for credit goods it is

$$
Y_{2 t}(z)=\min \left\{X_{1 t}(z), X_{2 t}(z) / S\left(z, q_{t}\right)\right\}
$$

To facilitate analysis, it is assumed that $S\left(z, q_{t}\right)=q_{t} \mathcal{S}(z)$ is strictly increasing in $z$ and that $\mathcal{S}(0)=0$. That is, all types of final goods are sorted according to the amount of credit services they require. Goods with higher indexes require more credit service input.

In equation (5), the variable $q_{t}$ is interpreted as a transaction technology shock and it follows a stationary stochastic process which includes deterministic seasonal components:

$$
\ln q_{t}=\ln q_{t}^{d}+\ln \tilde{q}_{t}
$$

where $\ln q_{t}^{d}=\sum_{s=1}^{4} q_{s} D_{s t}$ is the seasonal component and $\ln \tilde{q}_{t}$ is the stochastic part.

Aggregate goods $Y_{t}$ is produced according to the Leontief aggregation technology ${ }^{7}$

$$
Y_{t}=\inf \left\{Y_{t}(z)\right\}
$$

Given the constant returns to scale technologies in (1), (4), (5), and (7), the relative price of credit services in terms of the cash goods (the numeraire) is one, and the factor prices are determined by the marginal products. The following equations characterize the profit maximization behavior of all the producers.

$$
\begin{aligned}
W_{t}=A_{t} F_{2}\left(K_{1 t}, A_{t} N_{1 t}\right) & =A_{t} F_{2}\left(K_{2 t}, A_{t} N_{2 t}\right), \\
R_{t}^{k}=F_{1}\left(K_{1 t}, A_{t} N_{1 t}\right) & =F_{1}\left(K_{2 t}, A_{t} N_{2 t}\right),
\end{aligned}
$$

where $W_{t}$ is the real wage, $R_{t}^{k}$ is the rental rate of capital, and

$$
\frac{P_{2 t}(z)}{P_{1 t}}=1+q_{t} \mathcal{S}(z)
$$

where $P_{2 t}(z)$ is the price of credit goods of type $z, P_{1 t}$ is the price of the cash goods. Notice that equation (7) implies that $P_{1 t}$ is independent of the index $z$.

\footnotetext{
${ }^{7} \mathrm{~A}$ more general aggregator will not change the results of this paper. However, the Leontief form is much more tractable.
} 
Now let's turn to the behavior of households. The representative household derives utility from consumption of aggregate goods and leisure time. Assume that the household's preferences can be represented by

$$
E_{0} \sum_{t=0}^{\infty} \beta^{t} U\left(\theta_{t}, \hat{C}_{t}, l_{t}\right), \quad 0<\beta<1 .
$$

where

$$
\begin{gathered}
\hat{C}_{t}=C_{t}+\pi C_{t-1}, \\
l_{t}=T-N_{t},
\end{gathered}
$$

$E$ is the expectation operator, and $\beta$ is a discount factor. The total endowment of time $T$ is divided between leisure time $l_{t}$ and labor hours $N_{t}$. The household derives utility from both current and previous period consumption purchases $C_{t}$ and $C_{t-1}$ if $\pi \neq 0$. Positive values of $\pi$ indicate local durability in consumption (Dunn and Singleton, 1986); negative $\pi$ implies habit persistence (Constantinides, 1990). If $\pi=0$, preferences become time-separable in consumption. The term $\theta_{t}$ is a deterministic preference seasonal shifter given by

$$
\theta_{t}=\sum_{s=1}^{4} \theta_{s} D_{s t}, \quad \theta_{s}>0 \quad \forall s .
$$

The purchase of aggregate goods $Y_{t}$ can be used as either consumption goods which directly generate utility or capital goods which can be invested to firms. That is,

$$
Y_{t}=C_{t}+K_{t+1}-(1-\delta) K_{t} .
$$

where $K_{t}$ is the period $t$ stock of capital and $\delta$ is the capital depreciation rate.

The household can decide what fraction of the total purchase is in the form of cash goods or credit goods. Since $\mathcal{S}(z)$ is increasing, the credit goods price is increasing in $z$. On the other hand, the cash goods price is constant for all $z$. Thus there exists a cut-off index $z_{t}^{\star}$ so that the household purchases all goods indexed $z>z_{t}^{\star}$ by cash, and those indexed $z \leq z_{t}^{\star}$ as credit goods ${ }^{8}$. Since all types of goods are purchased in equal quantity, the total amount of credit goods purchased is $z_{t}^{\star} Y_{t}$, and for cash goods it is $\left(1-z_{t}^{\star}\right) Y_{t}$ (See Figure 1 ).

The household enters period $t$ with a money balance of $M_{t}$ and nominal bond holding of $B_{t}$. Prior to the opening of a centralized securities market, the household receives a lump-sum transfer of $H_{t}$ from the government. In the securities market, the household will

\footnotetext{
${ }^{8}$ Without loss of generality, we assume that $z_{t}^{\star}$ is purchased as credit goods, although it really doesn't make a difference for the household to purchase it by cash.
} 
rearrange her portfolio of money and bonds. Upon completion of these transactions, the securities market is closed and goods markets are open. The household's purchase of cash goods is subject to the cash-in-advance constraint

$$
Y_{t}\left(1-z_{t}^{\star}\right) \leq\left(M_{t}+H_{t}+B_{t}-\frac{B_{t+1}}{1+R_{t}}\right) / P_{1 t}
$$

where $R_{t}$ is the nominal interest rate.

At the end of the period, the household receives wages for hours worked, and rentals for capital from each firm. This income along with the real balance leftover after purchasing the cash goods will be used to purchase credit goods or accumulate money balance for the next period. Since the household only purchases the goods of type $z \leq z_{t}^{\star}$ as credit goods, the total spending on credit goods is $\int_{0}^{z_{t}^{\star}} Y_{t} P_{2 t}(z) d z$. So the budget constraint is

$$
\begin{aligned}
& \left(\int_{0}^{z_{t}^{\star}} Y_{t} P_{2 t}(z) d z+M_{t+1}\right) / P_{1 t} \leq \\
& \quad\left(M_{t}+H_{t}+B_{t}-\frac{B_{t+1}}{1+R_{t}}\right) / P_{1 t}-Y_{t}\left(1-z_{t}^{\star}\right)+W_{t} N_{t}+R_{t}^{k} K_{t} .
\end{aligned}
$$

The household maximizes life time expected utility (11) subject to the constraints (15), (16), and (17). The first order necessary conditions for the household's maximization problem are

$$
\begin{aligned}
\frac{U_{c}(t)}{U_{l}(t)} & =\frac{1+\tau_{t}}{W_{t}} \\
U_{c}(t) & =\beta \mathrm{E}_{t}\left[U_{c}(t+1)\left(1-\delta+\frac{R_{t+1}^{k}}{1+\tau_{t+1}}\right)\right], \\
\frac{U_{c}(t)}{1+\tau_{t}} & =\beta \mathrm{E}_{t}\left[\frac{U_{c}(t+1)}{1+\tau_{t+1}} \frac{P_{1 t}}{P_{1, t+1}}\left(1+R_{t+1}\right)\right] \\
1+R_{t} & =\frac{P_{2 t}\left(z_{t}^{\star}\right)}{P_{1 t}} \\
U_{c}(t) & =U_{\hat{c}}(t)+\beta \pi \mathrm{E}_{t}\left[U_{\hat{c}}(t+1)\right]
\end{aligned}
$$

where

$$
1+\tau_{t}=\left(1-z_{t}^{\star}\right)\left(1+R_{t}\right)+\int_{0}^{z_{t}^{\star}} P_{2 t}(z) d z / P_{1 t}
$$

and $\hat{C}_{t}=C_{t}+\pi C_{t-1}$ is the consumption service, $U_{c}(t)$ and $U_{l}(t)$ are the marginal utility of consumption and leisure, respectively, and $U_{\hat{c}}(t)$ is the marginal utility of consumption services.

The variable $\tau_{t}$ is interpreted as the effective inflation tax rate. If the nominal interest rate $R_{t}$ is positive, the opportunity cost of holding cash balance is positive. So the consumer will economize on cash holding and purchase a positive fraction of goods by credit. Since the 
fraction of cash goods purchased is $1-z_{t}^{\star}$, the opportunity cost for cash goods purchasing is $\left(1-z_{t}^{\star}\right)\left(1+R_{t}\right)$. Similarly, the cost incurred by the credit goods purchasing is $\int_{0}^{z_{t}^{\star}} P_{2 t}(z) d z / P_{1 t}$. So if there is positive inflation, the total cost for one dollar worth of aggregate goods is given by the right hand side of equation (23). If there is no inflation, that is, if $R_{t}=0$, the consumer will choose to purchase all types of goods using cash. In this case, the cost of a dollar worth of aggregate goods is one, so the effective inflation tax rate is $\tau_{t}=0$.

Equation (18) is similar to that in standard monetary growth models. It states that the marginal rate of substitution between leisure and consumption is equal to the ratio of the price of consumption goods to the real wage, adjusted by inflation tax. Equation (19) is the intertemporal capital accumulation condition. It is identical to that in a standard real business cycle model except that the return on capital is adjusted by inflation tax. This is because part of the investment goods are purchased by cash. This equation states that if the household purchases one unit of consumption goods at period $t$, the utility gained is $U_{c}(t)$; on the other hand, since this unit of goods is consumed, capital investment will have to be reduced by one unit, the cost is the real return to capital adjusted by inflation tax. The expected utility loss conditional on date $t$ information is given by the right hand side. On the margin, the gain and the loss must be equal, so equation (19) holds. Equation (20) is the Fisher type of relation between the nominal interest rate, inflation rate, and real interest rate. Notice that since consumption goods are subject to an inflation tax, the equation is slightly different from that in a standard monetary model in which the inflation tax is $1+R_{t}$. Condition (21) is a no-arbitrage condition between the cash goods and credit goods on the margin. The consumer can either purchase an additional unit of cash goods at price $P_{1 t}$ by borrowing at interest rate $R_{t}$, or purchase a unit of credit goods on the margin with index $z_{t}^{\star}$ at price $P_{2 t}\left(z_{t}^{\star}\right)$. Since cash goods and credit goods are perfect substitutes from the consumer's point of view, this condition has to hold. Finally, equation (22) is the definition of the marginal utility of consumption goods in terms of the marginal utility of consumption services. The period $t$ consumption not only affects current period utility, but also the utility of the next period, as long as $\pi \neq 0$.

To complete the description of the economy, I need to specify government policy. Since I am interested in the impact of monetary shocks and not the impact of fiscal policy, I set the government spending to a constant for all $t \geq 0$, in particular, it is set to equal to zero. Therefore, the government can use money injection to directly finance the lump-sum transfer 
and retire the government debt. That is,

$$
H_{t}=M_{t+1}^{s}-M_{t}^{s}+\frac{B_{t+1}^{s}}{1+R_{t}}-B_{t}^{s}, \quad \text { with } \quad B_{0}^{s} \text { given, }
$$

where $M_{t}^{s}$ is the money supply of period $t-1, B_{t}^{s}$ is the government bond redeemable at period $t$, and it is assumed that $B_{0}^{s}$ plus the expected presented value of net transfer payments equals the expected present value of seigniorage revenue.

As pointed out by Cooley and Hansen (1995), an implication of Ricardian equivalence in this economy is that, given $B_{0}^{s}$ and a particular realization of the money supply process, the time paths of $\left\{B_{t}^{s}, t \geq 1\right\}$ and $\left\{H_{t}, t \geq 1\right\}$ do not affect equilibrium allocations, provided that the present value government budget constraint is satisfied. Thus, the two methods of money injection are equivalent. Without loss of generality, we assume that $B_{t}^{s}=0$ for all $t \geq 1$, and that $B_{0}^{s}=0$. The government policy in (24) is then simplified to

$$
H_{t}=M_{t+1}^{s}-M_{t}^{s}
$$

The per capita money supply is assumed to grow at a rate of $g_{t}-1$. Thus,

$$
M_{t+1}^{s}=g_{t} M_{t}^{s}
$$

where, the variable $g_{t}$ is assumed to be a stationary stochastic process which includes deterministic seasonal components:

$$
\ln g_{t}=\ln g_{t}^{d}+\ln \tilde{g}_{t}
$$

where $\ln g_{t}^{d}=\sum_{j=s}^{4} g_{s} D_{s t}$ and $\ln \tilde{g}_{t}$ is the stochastic component of $\ln g_{t}$.

For the policy experiments that will be conducted, I will also consider an alternative policy scheme in which the government chooses the nominal interest rate $R_{t}$ as a policy instrument, in which case the money growth rate $g_{t}$ would be endogenously determined ${ }^{9}$.

- To capture empirical characteristics of alternative monetary policy, I assume that the vector process $\left\{\tilde{\lambda}_{t}, \ln \tilde{q}_{t}, \ln \tilde{g}_{t}\right\}$ is stationary and ergodic and has the following autoregressive representation:

$$
\left(\begin{array}{c}
\tilde{\lambda}_{t} \\
\ln \tilde{q}_{t} \\
\ln \tilde{g}_{t}
\end{array}\right)=B_{0}+B(L)\left(\begin{array}{c}
\tilde{\lambda}_{t-1} \\
\ln \tilde{q}_{t-1} \\
\ln \tilde{g}_{t-1}
\end{array}\right)+\left(\begin{array}{c}
\varepsilon_{\lambda t} \\
\varepsilon_{q t} \\
\varepsilon_{g t}
\end{array}\right)
$$

\footnotetext{
${ }^{9}$ As noted by many authors, if $R_{t}$ is taken as exogenous, there is a nominal indeterminacy problem. For simplicity, I follow Carlstrom and Fuerst's(1995) approach to resolve this issue.
} 
To summarize the description of the environment, there are six markets in this economy: the goods market, the credit service market, the labor market, the capital market, the money market, and the bond market. The respective market-clearing conditions are given by

$$
\begin{aligned}
C_{t}+K_{t+1}-(1-\delta) K_{t} & =F\left(K_{1 t}, A_{t} N_{1 t}\right), \\
\int_{0}^{z_{t}^{*}} Y_{t} q_{t} \mathcal{S}(z) d z & =F\left(K_{2 t}, A_{t} N_{2 t}\right), \\
N_{1 t}+N_{2 t} & =N_{t}, \\
K_{1 t}+K_{2 t} & =K_{t}, \\
M_{t} & =M_{t}^{s}, \\
B_{t} & =B_{t}^{s}=0 .
\end{aligned}
$$

\subsection{Competitive Equilibrium}

Having described the environment of the economy, we are ready to define a competitive equilibrium. Let $s_{t}$ be the state vector $\left(K_{t}, C_{t-1}, \lambda_{t}, q_{t}, g_{t}\right)^{\prime}$, and $s^{t}=\left(s^{t-1}, s_{t}\right)^{\prime}$ be the history of events.

Definition 1 A competitive monetary equilibrium in this economy is an allocation $\left\{C_{t}\left(s^{t}\right), N_{t}\left(s^{t}\right)\right.$, $\left.K_{t+1}\left(s^{t}\right), M_{t+1}\left(s^{t}\right), B_{t+1}\left(s^{t}\right)\right\}_{t=0}^{\infty}$, and a sequence of prices $\left\{P_{1 t}\left(s^{t}\right), R_{t}\left(s^{t}\right), W_{t}\left(s^{t}\right), R_{t}^{k}\left(s^{t}\right)\right\}_{t=0}^{\infty}$ such that

- Given $\left\{P_{1 t}\left(s^{t}\right), R_{t}\left(s^{t}\right), W_{t}\left(s^{t}\right), R_{t}^{k}\left(s^{t}\right)\right\}_{t=0}^{\infty}$, and initial $K_{0}\left(s_{0}\right), C_{-1}\left(s_{0}\right), M_{0}\left(s_{0}\right)$, and $B_{0}\left(s_{0}\right)=0$, the series $\left\{C_{t}\left(s^{t}\right), N_{t}\left(s^{t}\right), K_{t+1}\left(s^{t}\right), M_{t+1}\left(s^{t}\right), B_{t+1}\left(s^{t}\right)\right\}_{t=0}^{\infty}$ satisfy equations (16) - (23).

- The wage rate $W_{t}\left(s^{t}\right)$ and capital rental price $R_{t}^{k}\left(s^{t}\right)$ are determined by equations (8) and (9).

- All markets are cleared. That is, the allocation satisfies equations (29)-(34).

Since the productivity shock $A_{t}$ is a logarithmic random walk process, the above equilibrium conditions lead to a growth in consumption, investment, capital stock, output, real balance, and real wage, but not labor hours ${ }^{10}$. When one is interested in a stationary economy, it is necessary to remove this growth following the methods suggested by Christiano

\footnotetext{
${ }^{10}$ As pointed out by King, Plosser, and Rebelo (1988), the income effect and substitution effect of the productivity growth on labor supply must be netted out to ensure hours do not grow over time.
} 
(1988) and King, Plosser, and Rebelo (1988). Thus, the following transformation is made

$$
\begin{gathered}
C_{t}^{\star}=\frac{C_{t}}{A_{t}}, \quad K_{t}^{\star}=\frac{K_{t}}{A_{t-1}}, \quad Y_{t}^{\star}=\frac{Y_{t}}{A_{t}}, \quad K_{i t}^{\star}=\frac{K_{i t}}{A_{t-1}} \quad(i=1,2), \\
W_{t}^{\star}=\frac{W_{t}}{A_{t}}, \quad P_{1 t}^{\star}=\frac{A_{t} P_{1 t}}{M_{t+1}^{s}}, \quad M_{t}^{\star}=\frac{M_{t}}{M_{t}^{s}}, \quad B_{t}^{\star}=\frac{B_{t}}{M_{t}^{s}} .
\end{gathered}
$$

When these relations are substituted into equilibrium conditions (8) - (9), (16) - (23), and (29) - (34), one can obtain equilibrium conditions for the transformed variables and a stationary competitive monetary equilibrium can be defined in an analogous way.

The equilibrium allocations for this economy do not correspond to Pareto optimal allocations because of the distortionary effect of the inflation tax. Consequently the equilibrium allocations and prices cannot be calculated by solving the social planner's problem. Instead, the stationary equilibrium involving small fluctuations around steady state is approximated by solving a log-linearized version of equilibrium conditions for transformed variables. The steady state in this economy is a perfect foresight periodical equilibrium path. It is necessary to characterize this steady state equilibrium before we proceed to find a solution for the approximated equilibrium conditions.

Before describing the steady state equilibrium, it is helpful to express the aggregate resource constraint and factor prices in terms of transformed variables. Let $\phi_{t}$ be the valueadded share of the credit service sector in the aggregate output. Since the production functions for goods and credit services are identical (equation (1)), and constant returns to scale prevail in both sectors, the capital-labor ratios in the two sectors are identical and equal to the aggregate capital-labor ratio by equations (8), (9), (31), and (32). Hence, if we denote the aggregate output by $\hat{Y}_{t}$, then

$$
\hat{Y}_{t}=F\left(K_{1 t}, A_{t} N_{1 t}\right)+F\left(K_{2 t}, A_{t} N_{2 t}\right)=F\left(K_{t}, A_{t} N_{t}\right) .
$$

Let $X_{2 t}=F\left(K_{2 t}, A_{t} N_{2 t}\right)$ be the output of the credit service sector, and $Y_{t}=F\left(K_{1 t}, A_{t} N_{1 t}\right)$ be the output of the numeraire goods, then from the market clearing conditions (29) and (30), we have

$$
1 / \phi_{t}=\hat{Y}_{t} / X_{2 t}=\left(Y_{t}+X_{2 t}\right) / X_{2 t}=1+Y_{t} / X_{2 t}=1+1 / b_{t},
$$

where $b_{t} \stackrel{\text { def }}{=} \int_{0}^{z_{t}^{\star}} q_{t} \mathcal{S}(z) d z$, and the last equality follows from the market clearing condition for the credit service market (30). Thus the aggregate goods market clearing condition in terms of the transformed variables becomes

$$
C_{t}^{\star}+K_{t+1}^{\star}-(1-\delta) K_{t}^{\star}=\left(1-\phi_{t}\right) F\left(K_{t}^{\star} \exp \left(-\lambda_{t}\right), N_{t}\right)
$$


In addition, in terms of the aggregate transformed variables, the wage rate and capital rental rate are given by

$$
\begin{aligned}
W_{t}^{\star} & =F_{2}\left(K_{t}^{\star} \exp \left(-\lambda_{t}\right), N_{t}\right) \\
R_{t}^{k} & =F_{1}\left(K_{t}^{\star} \exp \left(-\lambda_{t}\right), N_{t}\right)
\end{aligned}
$$

The binding cash-in-advance constraint (16) implies that the equilibrium cutoff point between cash goods and credit goods is $z_{t}^{\star}=1-M_{t} /\left(P_{1 t} Y_{t}\right)$, and in terms of the transformed variables, it is

$$
z_{t}^{\star}=1-1 /\left(P_{1 t}^{\star} Y_{t}^{\star}\right)
$$

We now turn to characterize and compute the steady state equilibrium for this economy. We restrict attention to an equilibrium in which every variable $X$ has the characteristic that $X_{j+4}=X_{j}$ for all $j \geq 1$. So equilibrium variables repeat themselves every four quarters. In this economy, the steady state equilibrium can be found by solving the equilibrium conditions $((8)-(9),(16)-(23)$, and (29) - (34), with all uncertainties removed and with the condition $X_{j+4}=X_{j}, \forall j \geq 1$ being imposed for all variables $X$.

In practice, the perfect foresight path for transformed variables $\left\{C_{s}^{\star}, K_{s}^{\star}, P_{1 s}^{\star}\right\}_{s=1}^{4}$ can be solved from the Euler equations for the consumption-leisure decision, consumption-saving decision, and Fisher's relation. Given initial values for $\left\{C_{s}^{\star}, K_{s}^{\star}, P_{1 s}^{\star}\right\}_{s=1}^{4}, Y_{s}^{\star}$ can be solved from the goods market clearing condition. $Y_{s}^{\star}$ together with $P_{1 s}^{\star}$ will determine $z_{s}^{\star}$ by (40). Consequently, we can find the nominal interest rate $R_{s}$ from the money demand equation (21) given the relative price relation in (10). Then the effective inflation tax rate $\tau_{s}$ is determined by equation (23). The value-added share of the credit sector $\phi_{s}$ can be solved out from (36), given the value of $z_{s}^{\star}$. Then the aggregate goods market clearing condition (37) implies the value for labor hours $N_{s}$, given $C_{s}^{\star}$ and $K_{s}^{\star}$ for all $s=1, \cdots, 4$. With $N_{s}$ and $K_{s}^{\star}$, the wage and rental rates are obtained from (38) and (39), respectively. The optimization conditions used to find $\left\{C_{s}^{\star}, K_{s}^{\star}, P_{1 s}^{\star}\right\}_{s=1}^{4}$ are

$$
\begin{aligned}
\frac{U_{c}(s)}{U_{l}(s)} & =\frac{1+\tau_{s}}{W_{s}^{\star}}, \\
U_{c}(s) & =\beta U_{c}(s+1) \exp \left(-\lambda_{s+1}\right)\left[R_{s+1}^{k} /\left(1+\tau_{s+1}\right)+(1-\delta)\right], \\
\frac{U_{c}(s)}{1+\tau_{s}} & =\beta \frac{U_{c}(s+1)}{1+\tau_{s+1}} \frac{P_{1 s}^{\star}}{P_{1, s+1}^{\star} g_{s+1}}\left(1+R_{s+1}\right),
\end{aligned}
$$

where the $s=1, \cdots, 4$, and $X_{s+4}=X_{s}$ for all variables $X_{s}$ and all seasons $s$.

This leads to the following definition 
Definition $2 A$ sequence of quantities and price $\left\{C_{s}^{\star}, K_{s}^{\star}, P_{1 s}^{\star}\right\}_{s=1}^{4}$ is a seasonal steady state equilibrium if it satisfies equations (41) - (43).

The solution for the seasonal steady state equilibrium involves twelve nonlinear equations (there are three equations for each season). We use Newton's method to find solutions, and it turns out that different starting values always lead to the same solution. So the seasonal steady state equilibrium is stable.

Given the equilibrium paths for $\left\{C_{s}^{\star}, K_{s}^{\star}, P_{1 s}^{\star}\right\}_{s=1}^{4}$ and the seasonal shifters $\left\{\theta_{s}, \lambda_{s}, q_{s}, g_{s}\right\}_{s=1}^{4}$, the seasonal paths for other variables can be easily found as described above.

To solve for the stochastic equilibrium, we log-linearize the equilibrium conditions around the seasonal steady state equilibrium path calculated above. Let $\mu_{1 t}, \mu_{2 t}$, and $\mu_{3 t}$ be the Lagrangian multipliers associated with the cash-in-advance constraint (16), the budget constraint (17), and the equation defining the consumption services in terms of consumption goods (i.e. $\hat{C}_{t}^{\star}=C_{t}^{\star}+\pi C_{t-1}^{\star} \exp \left(-\lambda_{t}\right)$ ). Let $x_{t}$ denote the log-deviation of variable $X_{t}$ from the seasonal steady state equilibrium path, and $\tilde{\mu}_{j t}$ denote the counterpart for the Lagrangian multipliers. The linearized equilibrium conditions are summarized by

$$
M_{1} \mathrm{E}_{t}\left[\Gamma_{t+1}\right]=M_{2} \Gamma_{t}+M_{3} \mathcal{E}_{t}+M_{4} \mathrm{E}_{t}\left[\mathcal{E}_{t+1}\right]
$$

where $\Gamma_{t}$ is the column vector containing the five state and costate variables $k_{t}, c_{t-1}, \tilde{\mu}_{1 t}, \tilde{\mu}_{2 t}$, and $\tilde{\mu}_{3 t}$, and $\mathcal{E}_{t}$ is the column vector containing $\tilde{\lambda}_{t}, \ln \tilde{q}_{t}$, and $\ln \tilde{g}_{t}$. Since there are four different seasons, so (44) is a system of 20 equations. The matrices $M_{1}$ and $M_{2}$ are $20 \times 20$, and $M_{3}$ and $M_{4}$ are $20 \times 12$. Following Blanchard and Kahn (1980), one can show that a unique stationary solution exists for this class of economies when the matrix $M_{1}^{-1} M_{2}$ possesses twelve eigenvalues that are greater than one in absolute value and eight eigenvalues that are less that one in absolute ${ }^{11}$.

The linearized version of the equilibrium conditions given by (44) can be mapped into the state space representation described by King, Plosser, and Rebelo (1987) in a straight forward way. The equilibrium decision rules for capital stock and consumption are then described by

$$
S_{t+1}=M S_{t}+e_{t}
$$

where

$$
S_{t} \equiv\left(\vec{k}_{t}, \vec{c}_{t-1}, \vec{\lambda}_{t}, \vec{q}_{t}, \vec{g}_{t}\right)^{\prime}
$$

\footnotetext{
${ }^{11}$ This is true provided that appropriate transversality conditions are imposed.
} 
with $\vec{x}_{t} \stackrel{\text { def }}{=}\left(x_{t}^{1}, x_{t}^{2}, x_{t}^{3}, x_{t}^{4}\right)^{\prime}$, where the superscripts denote seasons, and

$$
e_{t} \equiv\left(\overrightarrow{0}, \overrightarrow{0}, \vec{\varepsilon}_{\lambda t}, \vec{\varepsilon}_{q t}, \vec{\varepsilon}_{g t}\right)^{\prime}
$$

in which $\overrightarrow{0}$ is a four dimensional vector of zeros, and $\vec{\varepsilon}_{\lambda t}$ is the vector of innovations for the technology shock corresponding to the four seasons.

The matrix $M$ in (45) links the state vector to the lagged states and exogenous forcing variables. Given the log-linear decision rules for capital stock and consumption, we can generate equilibrium time series for the model economy. To do this, we first draw a sequence of normally distributed random variables according to the covariance structure of the innovations $\varepsilon_{\lambda t}, \varepsilon_{q t}$, and $\varepsilon_{g t}$. Then given an initial $S_{0}$ we construct the series for capital stock and consumption using the methods described in Braun and Evans (1994). We can obtain other flow variables such as output, investment, hours, wage rate, capital rental rate, price level, inflation rate, and nominal interest rate based on the capital and consumption series and other equilibrium relations ${ }^{12}$. With the simulated series obtained, we can compute the first-moment and second-moment statistics easily.

To facilitate comparisons with other work, I follow Barsky and Miron's (1989) decomposition of the stationary processes into deterministic seasonal and stochastic components. After taking the first log-difference, each series is regressed on four seasonal dummy variables. The coefficients on the dummies correspond to the seasonal patterns emphasized by Barsky and Miron (1989). The residuals from the regression represent the business cycle phenomena.

\section{Parameter Values}

In this section we describe the data that will be used in our empirical analysis, the parameterization of the model, and finally the estimation of the structural parameters.

The data set employed in this study is the Barsky and Miron(BM) (1989) data which is quarterly U.S. data that has not been seasonally adjusted. The model implies a set of restrictions on the measurement. So we define the following variables. Consumption $(C)$ is the sum of nondurable and service expenditures per capita. Investment $(I)$ is the gross domestic fixed business investment plus durable consumption expenditures. Output $(Y)$ is the sum of consumption and investment. Capital stock $(K)$ is computed using the flow

\footnotetext{
${ }^{12}$ The details of the computation are available upon request from the author.
} 
investment expenditures, a quarterly depreciation rate of 0.025 , and an initial capital stock value for 1958. Labor hour $(N)$ is not chosen from the $\mathrm{BM}(1989)$ data set, instead it is the efficiency units constructed by Hansen (1991) based on the Current Population Survey, and is not seasonally adjusted; it is equal to the product of the number of workers and average hours. Money stock $(M)$ is the monetary base, adjusted for regulation changes, not adjusted for seasonality, published by the Board of Governors of the Federal Reserve System. Nominal interest rate $(R)$ is the Federal Funds Rate, not seasonally adjusted. Price level $(P)$ is the consumer price index from BM(1989). Average labor productivity and capital rental rate are constructed from the output, labor hours, and capital stock data. All the quantity variables including $C, I, Y, K, N$, and $M$ are converted into per capita values using the civilian population, 16 years and older. The sample period covers 1960:1-1984:4.

Given the seasonally unadjusted time series data of the U.S. economy, we can parameterize the model and find the structural parameters. As in King, Plosser, and Rebelo (1987, 1988), the steady state growth implies a set of restrictions on preference and technologies. My parameterization will take these into account. Specifically, I assume that the utility function and production function take the following forms

$$
U\left(\theta_{t}, C_{t}+\pi C_{t-1}, T-N_{t}\right)=\ln \left(C_{t}+\pi C_{t-1}\right)+\theta_{t} \ln \left(T-N_{t}\right)
$$

and

$$
F\left(K_{t}, A_{t} N_{t}\right)=K_{t}^{\alpha}\left(A_{t} N_{t}\right)^{1-\alpha} .
$$

In addition, it is assumed that

$$
\mathcal{S}(z)= \begin{cases}\frac{\eta}{\psi}\left(1-(1-z)^{\psi}\right) & \text { if } \psi \neq 0 \\ -\eta \ln (1-z) & \text { if } \psi=0\end{cases}
$$

Before we describe the estimation strategy, it is helpful to understand the role of the key parameters in this economy. First, let's see why a nonzero value of $\pi$ is important. Given the parameterization in (46) and (47), the optimal capital accumulation decision rule (19) becomes

$$
\mathrm{E}_{t}\left\{\beta \frac{U_{c}(t)}{U_{c}(t+1)} \tilde{R}_{t+1}^{k}-1\right\}=0,
$$

where $U_{c}(t)$ is the marginal utility of consumption at date $t$, and

$$
\tilde{R}_{t+1}^{k}=\alpha\left(\frac{A_{t} N_{t}}{K_{t}}\right)^{1-\alpha} \frac{1}{1+\tau_{t+1}}+(1-\delta)
$$


is the gross real interest rate adjusted for inflation tax. Suppose that $\pi=0$, then $\hat{C}_{t}=$ $C_{t}+\pi C_{t-1}=C_{t}$, and $U_{c}(t)=1 / C_{t}$. So equation (49) would be reduced to

$$
\mathrm{E}_{t}\left\{\beta \frac{C_{t}}{C_{t+1}} \tilde{R}_{t+1}^{k}-1\right\}=0 \text {. }
$$

This equation in turn implies the econometric relation

$$
\beta \frac{C_{t}}{C_{t+1}} \tilde{R}_{t+1}^{k}-1 \equiv u_{t+1}
$$

with $\mathrm{E}_{t}\left\{u_{t+1}\right\}=0$.

Given our assumption of the cointegration properties of quantity variables, and the assumption that seasonal components can be represented in terms of seasonal dummy variables, the variable $\left\{u_{t}\right\}$ is a purely indeterministic stochastic process. Consequently, any deterministic components of the processes $\left\{C_{t}\right\}$ and $\left\{\tilde{R}_{t+1}^{k}\right\}$ must net out from the left hand side of (50). However, this is not true given that the growth rate of consumption exhibits much stronger seasonality than the real interest rate in the U.S. seasonally unadjusted data. So in general, $\pi$ should not be zero. In this sense, the parameter $\pi$ performs the role of seasonal adjustment in (49).

Turning to the Solow residual term $\lambda_{t}$, notice that

$$
\lambda_{t}=\left[\Delta \ln Y_{t}-\Delta \ln \left(1-\phi_{t}\right)-\alpha \Delta \ln K_{t}-(1-\alpha) \Delta \ln N_{t}\right],
$$

where the variable $\phi_{t}$ is the value added share of the credit service sector in the gross output $\hat{Y}_{t}=K_{t}^{\alpha}\left(A_{t} N_{t}\right)^{1-\alpha}$ given by equation (36), and $\Delta$ is a first difference operator. Since the growth rate of capital stock has little seasonality, whereas output growth has stronger seasonal variations than labor hours in the data, the Solow residual $\lambda_{t}$ has to have a seasonal component.

-Now let's examine the role played by the transaction technology shock $q_{t}$. Given the parameterization of $\mathcal{S}(z)$, equations (10) and (21) imply that the money demand equation is

$$
R_{t}= \begin{cases}\frac{\eta}{\psi} q_{t}\left(1-\left(M_{t} /\left(P_{1 t} Y_{t}\right)\right)^{\psi}\right) & \text { if } \psi \neq 0 \\ -\eta q_{t} \ln \left(M_{t} /\left(P_{1 t} Y_{t}\right)\right) & \text { if } \psi=0\end{cases}
$$

Since the income velocity of money $M_{t} /\left(P_{1 t} Y_{t}\right)$ displays strong seasonal variations while the nominal interest rate is quite smooth across seasons, the seasonal components in $q_{t}$ captures all the residual movements between velocity and the nominal interest rate. 
Similarly, the preference seasonal shifter $\theta_{t}$ is necessary because it captures residual seasonality in the optimal consumption and leisure decision equation

$$
\frac{\theta_{t}}{T-N_{t}}=\frac{1}{1+\tau_{t}} U_{c}(t)(1-\alpha) \frac{Y_{t}}{N_{t}}
$$

We now turn to the choice of structural parameters values. The parameters $\beta, \delta, \eta, \psi, \pi$, and $T$ are either not formally identified or difficult to identify in the data. So we choose these parameters according to previous business cycle studies. Following Christiano and Eichenbaum (1992), we set the discount factor $\beta$ to $1.03^{-0.25}$. The depreciation rate $\delta$ is chosen to be $2.5 \%$ at a quarterly rate, as in Kydland and Prescott (1982). The parameter $\eta$ is a scale factor in the money demand equation (52), so we set it to be unity. $\psi$ governs the interest elasticity of money demand, we have tested the influence on the numerical results for $\psi$ varying from -4 to 2 , and find that the equilibrium patterns are not sensitive to the choice of $\psi$. So a value of 0.2 is chosen. The parameter $\pi$ governs the degree of intertemporal substitution of consumption. Using seasonally adjusted data, Dunn and Singleton (1986) have estimated $\pi$ to be between 0.27 and 0.58 . The estimate obtained by Eichenbaum, Hansen, and Singleton (1988) ranges from 0.40 to 0.73 . Using seasonally unadjusted data, the estimate obtained by Braun and Evans (1991) is 0.45. So we choose $\pi=0.65$ in light of previous studies. Finally, the total hours per quarter $T$ is set to 1369 , following Christiano and Eichenbaum (1992).

The parameters to be estimated are

$$
\boldsymbol{\Psi}=\left\{\alpha, q_{1}, q_{2}, q_{3}, q_{4}, \lambda_{1}, \lambda_{2}, \lambda_{3}, \lambda_{4}, \theta_{1}, \theta_{2}, \theta_{3}, \theta_{4}\right\}
$$

plus the parameters governing the stochastic processes of the underlying shocks.

The transaction technology shock $q_{t}$ can be constructed from the inverse money demand equation (52) and we can obtain $\left[q_{1}, q_{2}, q_{3}, q_{4}\right]$ by regressing $q_{t}$ on four seasonal dummies.

Given the implied series $q_{t}$, we can construct the time series for the effective inflation tax rate $\tau_{t}$ from (23). The capital income share parameter $\alpha$ is then identified by the equilibrium capital accumulation decision equation (19):

$$
\mathrm{E}\left\{\beta^{-1}-\frac{U_{c}(t)}{U_{c}(t+1)}\left[1-\delta+\alpha \frac{Y_{t+1}}{K_{t+1}} \frac{1}{1+\tau_{t+1}}\right]\right\}=0,
$$

where $U_{c}(t)$ denote the marginal utility of consumption at time $t$.

The Solow residual term $\lambda_{t}$ is constructed from equation (51), given the values of $\alpha$ and $\phi_{t}$. The series $\phi_{t}$ is obtained from equation (36), given the series $q_{t}$. The seasonal parameters $\left[\lambda_{1}, \lambda_{2}, \lambda_{3}, \lambda_{4}\right]$ are then obtained by regressing $\lambda_{t}$ on four seasonal dummies. 
The preference seasonal shifters $\left[\theta_{1}, \theta_{2}, \theta_{3}, \theta_{4}\right]$ are chosen to match the seasonal means of the log-growth rate of labor hours ${ }^{13}$. From the intratemporal consumption-leisure decision equation (18),

$$
\tilde{\theta}_{t}=\frac{(1-\alpha) Y_{t}\left(T-N_{t}\right) U_{c}(t)}{\left(1+\tau_{t}\right) N_{t}}
$$

The regression coefficients of $\tilde{\theta}_{t}$ on the seasonal dummies are used as an initial guess for the seasonal parameters $\left[\theta_{1}, \theta_{2}, \theta_{3}, \theta_{4}\right]$.

Finally, we need to find the parameters governing the stochastic components of the shock variables in equation (28). Since all the random variables are mean zero, so $B_{0}$ is a zero vector. Thus the parameters to be estimated are those in the matrices $B(L)$ and $\Sigma=$ $\operatorname{var}\left(\varepsilon_{t}\right)$, which can be obtained by estimating a tri-variate VAR with one lag, using the conditional maximum likelihood method as in Hamilton (1994). If a parameter turns out to be statistically insignificant, it is set to equal zero ${ }^{14}$.

Table 1 presents the estimation results of the structural parameters. The data set runs from the first quarter of 1960 to the fourth quarter of 1984. There are several notable features in the parameter values presented in Table 1. First, the capital income share is estimated to be 0.41 , which is larger than the estimates obtained by Braun and Evans (1994). The reason is that the output measure here is the sum of consumption and investment, instead of GNP, as used by Braun and Evans.

Secondly, the estimates display a large degree of seasonal variations in technology. The productivity growth has a sharp drop of nearly $14 \%$ in the first quarter, recovers substantially in the second quarter, and then continues to grow at a moderate pace in the last two quarters. This estimated technology seasonal is similar to that in Christiano and Todd (1995) but the magnitude is larger ${ }^{15}$. The first quarter downturn may be due to weather and seasonality in construction, as suggested by Barro (1993). But Beaulieu and Miron (1992) find that output

\footnotetext{
${ }^{13}$ This is implemented by repeated simulations of the model to minimize a quadratic loss function. Specifically, given an initial guess of the $\theta$ 's, along with all other parameters calibrated above, we can solve for the seasonal steady state equilibrium and find the model's predictions about the seasonal patterns of labor hours. The distance between the model's prediction and the "true" patterns from the data is measured by a quadratic loss function. The Matlab function fmins is called to minimize this loss function, choosing the $\theta$ 's. A good initial guess is important to assure fast convergence and accuracy.

${ }^{14}$ To test the VAR(1) specification, we have performed a likelihood ratio test as proposed by Sims(1980). The null hypothesis that the set of stochastic variables was generated from a Gaussian VAR with one lag against the alternative specification of two lags (or four lags) is accepted at a $5 \%$ critical value.

${ }^{15}$ Using GNP as a measure of output and the same labor hours series as here, they find that there is a $10 \%$ decline of technology growth rate in the first quarter.
} 
falls in the first quarter in some countries in the Southern Hemisphere such as Argentina and Australia. In addition, it is difficult to explain the output rise in the fourth quarter based on weather. The magnitude of technology seasonal swings is implausibly large, as pointed out by Braun and Evans (1994) ${ }^{16}$. This may be attributed to two factors. First, the model abstracts away from government spending, and uses consumption plus investment as the measure of output, instead of gross domestic product. Since government spending has much less seasonal variations than consumption and investment, the output measure displays a larger seasonal variation than GDP. Secondly, and more importantly, the model does not consider variations of unobserved labor efforts and effective capital utilization rate, but instead, puts all the burden of capturing the difference between the seasonal swings in output and input variables on the Solow residual term ${ }^{17}$. However, given that our objective is to evaluate welfare consequences of alternative monetary policies, we choose to approximate the technology seasonality using Solow residuals since this is more tractable than other alternatives.

Thirdly, the preference seasonal has a first quarter trough and a third quarter peak, which can be interpreted as a "vacation effect". In the third quarter, people tend to work less and spend more time on vacations. ${ }^{18}$.

Lastly, the transaction technology has a strong seasonal variation. In the first quarter $q_{t}$ is highest, and it drops slightly in the second and third quarter, then reaches its lowest level in the fourth quarter. Recall that when $q_{t}$ is high, the required credit service to produce each unit of credit good is high. So higher $q_{t}$ is a "negative shock" to the transaction technology. The weather effect is unlikely to explain the seasonal variations in $q_{t}$. Due to

\footnotetext{
${ }^{16}$ The estimates of the Solow residual seasonal are not directly comparable to Braun and Evans's(1994) results since they use a different measure of output and labor hours.

${ }^{17}$ Braun and Evans (1991) construct a model which take the labor efforts and capital utilization rate into consideration, and find that even though there are no seasonals in the Solow residuals, and the only source of seasonal fluctuations is from preference shifts, their model can still explain output seasonal variations.

${ }^{18}$ The efficiency units of labor hours magnifies the seasonal variations in the preference shifter, relative to the labor hours series based on the Establishment Survey which is used by Braun and Evans (1994) and Barsky and Miron (1989). The way of constructing the efficiency units of hours is to assign low weights to hours worked by young and inexperienced workers whose relative average wage rates are low. A rise in hours worked by this category of workers will produce a smaller rise in "effective hours worked" than the same increase in hours by older, more experienced workers. So in the third quarter, when many experienced workers go on vacation and many students work part time or for low wage jobs, there is a decline in the effective hours worked.
} 
the (un)availability of data for the output of the credit service sector, it is hard to interpret the seasonal movements in this sector. However, casual observation suggests that this may be attributed to the seasonal change in the composition of business activities and household activities. Specifically, business activities usually require more credit transactions relative to the household sector, and in general the business sector is more efficient in using credit services due to the large volume of credit transactions (economies of scale). During seasons when business activities are high, the required credit services for each unit of credit transactions tend to go down.

\section{Evaluation of the Model}

The model is solved using the strategies laid out in section 2. The technology growth process implies that variables including output, consumption, investment, capital stock, real balance, and average labor productivity are all first-difference stationary. So I report results based on data that are first differenced. I take a position that any arbitrary filtering may distort the property of the data in an unpredictable way. Since first differencing is consistent with my model, this is the only method I use to induce stationarity.

To evaluate the model's empirical plausibility, I compare the model's predictions with both the seasonal and cyclical patterns in the U.S. data. To facilitate these comparisons, I follow Barsky and Miron's decomposition of a stationary, stochastic process into a deterministic seasonal component and a stochastic component. In particular, the first-differenced series are regressed on four seasonal dummy variables corresponding to the four seasons. The estimated coefficients on the dummies represent the seasonal patterns emphasized by Barsky and Miron (1989). The second moment properties of the regression residuals correspond to the business cycle phenomena stressed by Prescott (1986).

\subsection{Seasonal Predictions}

Table 2 presents the seasonal patterns of some key variables predicted by the model and those in the U.S. data ${ }^{19}$. The left panel is the estimates from the data, and the right panel contains the simulation results from the model. The numbers reported are seasonal means of growth rates for each series, and they are in terms of percentage deviations from the (nonseasonal) average growth rates. The sample period runs from quarter one of 1960 to

\footnotetext{
${ }^{19}$ Figure 6 presents the same information graphically.
} 
quarter four of 1984 All variables except for the capital rental rate (the real interest rate), nominal interest rate, and inflation rate are logged before taking the first difference. The first difference filter is applied to the levels of the real interest rate and nominal interest rate, while in the case of the inflation rate, only the annualized level is reported. The standard errors for each estimated coefficients on the seasonal dummies are computed based on the Newey-West(1987) weighting matrix with 12 autocorrelation lags.

Before we formally judge the model's seasonal performance, it is helpful to identify the variables that provide independent information for evaluating the model. In section 3 , we have seen that the preference seasonal shifters $\theta_{t}$ are chosen to match the seasonal patterns of labor hours. Given this choice, since capital stock does not have much seasonality both in the data and in the model, and the Solow residual term $\lambda_{t}$ is calculated to capture all "residuals" unaccounted for between output and input variables, so output should be closely matched. This is indeed the case: the model's predictions about output seasonals lie within the two standard deviation band of the estimates in the data (Figure 5). Given the match for labor hours, capital stock, and output, average productivity and capital rental rate do not contain independent information to evaluate the model since they are exact functions of the above variables. On the other hand, consumption and investment do not contain independent information because one implies the other given the resource constraint (37) and the match for output. So on the real side of the economy, it is sufficient to examine the model's performance by looking at its predictions on either investment or consumption. Turning to the nominal variables, since the transaction technology seasonal shifter $q_{t}$ is chosen to capture the residuals between velocity and the nominal interest rate, we need to examine the model's prediction of only one of these two variables. In summary, the variables containing independent information for model evaluation purposes include investment (or consumption), the inflation rate, and the nominal interest rate (or velocity). These variables are shown in Figure 5.

In this figure, the solid lines represents seasonal means of the growth rates in the data, and the dashed lines are the model's predictions. The two standard deviation bands for the estimates from the data are also displayed (the dashed- dotted lines). On the real side of the economy, we see that the model has successfully captured the seasonal patterns of investment, but the magnitude is too large relative to the data. This is because the seasonal variations of the economy are perfectly anticipated, so an important source of consumption variability, unanticipated income effects, is not present. The consumer can plan ahead of time to smooth 
consumption by drawing down or building up investment ${ }^{20}$. However, the magnitude of investment seasonals would have been more dramatic if the local durability of consumption were absent. With local durability, instead of smoothing consumption purchases across seasons, the consumer tries to smooth the consumption services which depend on both the current and the previous period consumption purchases. The consumer can do so by adjusting either savings or consumption purchases. That is, the consumer has an additional means to smooth consumption services. The magnitude of investment seasonal variations is thus partially offset by the seasonal movement in consumption purchases.

Turning to the model's predictions of nominal variables, the match to the data is quite well: both the inflation rate and the nominal interest rate from the model lie within the two standard deviation bands. This can be attributed to two key assumptions of the model. First, consumption durability increases the intertemporal elasticity of substitution in consumption, hence reduces the seasonal variations in real interest rates. On the other hand, the transaction technology shock (or shifter) $q_{t}$ captures the residual movements between velocity and the nominal interest rate in the money demand equation (52). It allows velocity to vary in response to exogenous shifts without large seasonal swings in the nominal interest rate $^{21}$. The consumption durability and transaction technology shock jointly produce dampened variations in both the real and nominal interest rates, hence the seasonal fluctuations in inflation are smoothed according to Fisher's relation.

\subsection{Cyclical Predictions}

We report the relative volatility and cross-correlations with output for the seasonally adjusted series in Table 3. The seasonal adjustment is implemented by removing seasonal dummies from the unadjusted series. The first column contains variables of interest. The second column contains the ratios of the standard errors of all variables to that of the output, with the first entry being the standard error of output. The third column is the contemporaneous correlation between each variable and output. Both the second and the third columns are computed from the model. They are obtained by simulating the model using the param-

\footnotetext{
${ }^{20}$ We have tested this intuition by setting the consumption durability parameter $\pi$ to zero, and kept other parameters unchanged. The resulting consumption shows little seasonal variation.

${ }^{21}$ The latter feature is not present in a standard cash-in-advance model as in Lucas and Stokey (1987) and Cooley and Hansen $(1989,1995)$. In those models, the nominal interest rate is an exact function of velocity, hence it covaries with velocity in a one-for-one manner.
} 
eterization as in Section 3. The reported statistics are sample averages based on 500 random draws of length 100. The fourth and fifth columns contain the statistics computed from the data with the sample ranging from 1960:01 to 1984:04.

With respect to relative variabilities, the model successfully predicts that consumption is less volatile than output while output is less variable than investment. But it overstates the fluctuations in output and understates the relative volatility of hours. These are all common features of standard real business cycle models. However, our model outperforms standard cash-in-advance models such as Cooley and Hansen (1995) in predicting the relative variabilities of nominal variables. The model correctly predicts that inflation, price level and nominal interest rate are all much less volatile than output. Again, this last feature is attributable to the consumption durability and the transaction technology shock as discussed above 22 .

Turning to the cross-correlations with output, the matches for both real and nominal variables are reasonably good. Specifically, the predicted correlation patterns for all real variables except for capital stock and labor hours match the data closely. The model correctly predicts that output is positively correlated with the inflation rate but negatively with price level, and that the nominal interest rate is procyclical, so is velocity.

In summary, the model performs as well as other standard real business cycle models concerning real variables of the economy, at the same time, it does better than standard cash-in-advance models on the nominal side.

\section{$5 \quad$ Policy Experiments}

In Section 4, I have demonstrated that the model replicates both the seasonal and cyclical patterns of the U.S. time series reasonably well. In this section, I will conduct several policy experiments based on this model. Specifically, the welfare associated with the historical monetary policy which smooths nominal interest rates across seasons and allows the interest rates to be procyclical is compared with two distinct alternatives. One is the constant-

\footnotetext{
${ }^{22}$ Notice that these two features of the model effectively insulate prices and the nominal interest rate from seasonal shifts in preferences and technologies. However, since the seasonal swings in productivity growth are too large in magnitude, the consumption durability "over-corrects" the cyclical variations in the inflation rate. A standard cash-in-advance model usually predicts that inflation rate is more volatile than output, which is counterfactual, but this model's prediction of the relative volatility of the inflation rate is too low compared to the data.
} 
money-growth rule advocated by Friedman $(1959,1982)$, which calls for smoothing money growth rates at both seasonal and business cycle frequencies; the other is the constantinterest-rate rule proposed by Carlstrom and Fuerst $(1995,1996)$, which suggests that the Fed should smooth nominal interest rates at both frequencies. Both alternative policy rules are restricted to produce the same steady state seigniorage revenue as the historical policy.

In practice, I compare the welfare associated with each of the three policy rules with the welfare under Friedman's rule which calls for zero nominal interest rates. In this economy, Friedman's rule is consistent with optimal allocation of resources, since it results in a zero inflation tax and hence no resources being used in the credit service production. However, in order to make the welfare experiments interesting, I assume that the government is required to raise a positive seigniorage revenue ${ }^{23}$. Thus, Friedman's rule is infeasible since it does not produce the required seigniorage revenue. Nonetheless, the welfare under Friedman's rule is the highest that the economy can achieve, so it provides a natural benchmark for welfare comparisons. The measure of welfare loss is defined as the percentage increase in consumption that is required to make the consumer's life-time discounted utility equal to that in in the economy under Friedman's rule. The welfare under Friedman's rule is computed by setting the nominal interest rate to zero and simulating the model economy conditional on the structural parameters. Upon getting the simulated consumption service flow and the leisure time series, the life-time discounted utility of the representative agent can be computed in a straightforward way. Similarly, conditional on each of the alternative monetary policies, we can simulate the model economy and get the life-time discounted utility of the consumer under each policy rule. Tables 4 and 5 present the welfare costs associated with each of the three alternative monetary policies. The numbers reported are averages of 300 random draws. Table 4 reports the welfare comparisons for the economy at the seasonal steady state equilibrium, and Table 5 reports the counterparts for the dynamic stochastic equilibrium path.

Two findings are in order. First, the interest rate rule dominates the money growth rule in terms of social welfare. The welfare loss associated with the interest rate rule compared to Friedman's rule is $0.48 \%$ of consumption for the seasonal steady state equilibrium path,

\footnotetext{
${ }^{23}$ The government may raise revenues by imposing taxes, issuing debts, and printing money. As discussed by Aiyagari and Braun (1996), if there are costs in raising tax revenues (such as tax filing time, operation costs of IRS, etc.), then it might be optimal for the government to collect positive seigniorage revenues by printing money. In addition, as Barro (1989) points out, a positive tax rate on money allows the government to tax some black-market activities where the final product is not taxed.
} 
and $1.20 \%$ for the dynamic stochastic equilibrium path. For the money growth rule, these losses are $0.64 \%$ and $1.45 \%$, respectively. In terms of U.S. real consumption in 1996 (\$4687 billion), these numbers are translated into a welfare difference of $\$ 7.2$ billion for the steady state, and $\$ 11.5$ billion for the dynamic path. This finding is consistent with Barro's(1979) tax smoothing argument, since the interest rate smoothing policy effectively smoothes the inflation tax rate if the primary source of shocks is productivity shocks and preference shifts ${ }^{\mathbf{2 4}}$. Second, the historical policy which smoothes the nominal interest rate across seasons and allows it to be procyclical dominates both the constant-interest-rate rule and the constantmoney-growth rule in terms of social welfare. The historical policy produces a welfare loss of $0.95 \%$ of consumption in perpetuity, compared with a $1.2 \%$ and a $1.45 \%$ loss associated with the interest rate rule and the money growth rule, respectively. The intuition is as follows. In a standard real business cycle world, the real interest rate is strongly procyclical. According to the Fisher's equation, since the inflation rate is weakly correlated with output, if the nominal interest rate is procyclical, it would allow the real interest rate to comove with output. Since the equilibrium allocations in a real business cycle economy are Pareto optimal, the procyclical nominal interest rate is "closer" to being more efficient than other policy alternatives.

The latter finding extends Poole's (1970) insights about the choice of monetary policy rules to a dynamic and stochastic environment. Poole argues that interest rate smoothing is desirable if the shocks are in money demand; on the other hand, if the shocks from goods market dominate, allowing interest rates to co-move with output is a sensible policy. In my model, the transaction technology shock acts like a money demand shock, and it is more important at the seasonal frequency, so seasonal interest rate smoothing is desirable. Over business cycles, however, the effects of the more persistent technology shocks build up and the less persistent transaction technology shocks average out, so procyclical interest rate policy is sensible.

Finally, from Table 6, the interest rate rule produces a higher variability in the inflation rate than either the money growth rule or the observed policy. On the other hand, the money growth rule is associated with the highest output volatility. The differences, however, are insignificant.

\footnotetext{
${ }^{24}$ Mankiw and Miron (1991) find similar results in a seasonal context. But they use a partial equilibrium IS-LM framework.
} 


\section{Conclusion}

Since the establishment of the Federal Reserve System in 1913, its monetary policy has produced non-seasonal behavior of nominal interest rates. At the same time, the Fed has allowed interest rates to be procyclical at the business cycle frequency. Although researchers have found striking empirical similarities between seasonal cycles and business cycles, the Fed has been conducting these asymmetric policies throughout its history. This paper has studied the consequences and desirability of these policies, based on a theoretical framework which can explain both the seasonal and business cycle phenomena in the U.S. economy.

The findings in this paper can be summarized as follows. First, the neoclassical monetary growth model featuring consumption durability and a transaction technology shock is able to explain many important aspects of seasonal cycles and business cycles in the U.S. economy. In particular, the model is more successful in matching nominal U.S. aggregate variables than traditional cash-in-advance models. Secondly, the historical U.S. monetary policy yields higher welfare than both the constant-interest-rate rule and the constant-moneygrowth rule. These findings suggest that the Fed has been sensibly choosing its monetary policy in response to seasonal variations and business cycle fluctuations, instead of creating exogenous disturbances to the economy.

The welfare analysis can be extended along two dimensions. First, the model economy investigated in this paper is an aggregate economy. As in many related recent studies, the model predicts small aggregate welfare differences among alternative monetary policy rules. It suggests that monetary policy may be motivated by income distribution considerations in addition to aggregate welfare. However, to examine the income distribution effects of seasonal and cyclical monetary policies, one needs to investigate an economy with heterogeneous agents.

Secondly, in the monetary economy considered in this paper, as in many traditional monetary models, Friedman's rule which requires nominal interest rates to be zero is consistent with optimal allocation of resources. However, Friedman's rule has almost never been implemented by the monetary authority. The question is whether there are sound economic reasons for the Fed not to follow this rule. In economies in which Friedman's rule is not optimal, how would the evaluation of the seasonal and cyclical monetary policy differ from the current analysis? These are interesting topics for future research. 


\section{References}

[1] Aiyagari, S. Rao and R. Anton Braun, 1996, Some explorations into optimal cyclical monetary policy, Manuscript, Federal Reserve Bank of Minneapolis.

[2] Aiyagari, S. Rao, R. Anton Braun, and Zvi Eckstein, 1995, Transaction services, inflation, and welfare, Working Paper 551, Federal Reserve Bank of Minneapolis.

[3] Barro, Robert J., 1993, Macroeconomics, 4th ed. (Wiley, New York).

[4] Barro, Robert J., 1989, Interest-rate targeting, Journal of Monetary Economics 23, 3-30.

[5] Barro, Robert J., 1979, On the determination of the public debt, Journal of Political Economy 87, 940-971.

[6] Barsky, Robert B. and Jeffrey A. Miron, 1989, The seasonal cycle and the business cycle, Journal of Political Economy 97, 503-535.

[7] Beaulieu, J. Joseph and Jeffrey A. Miron, 1992, A cross country comparison of seasonal cycles and business cycles, Economic Journal 102, 772-788.

[8] Blanchard, Olivier J. and Charles M. Kahn, 1980, The solution of linear difference models under rational expectations, Econometrica 48, 1305-1311.

[9] Braun, R. Anton and Charles L. Evans, 1994, Seasonality and equilibrium business cycle theories, Journal of Economic Dynamics and Control 19, 503-531.

[10] Braun, R. Anton and Charles L. Evans, 1991, Seasonal Solow residuals and Christmas: A case for labor hoarding and increasing returns, Manuscript (Federal Reserve Bank of Chicago, Chicago, IL)

[11] Cagan, Philip, 1971, Changes in the cyclical behavior of interest rates, in:Guttentag, J.M., ed, Essays on interest rates, Vol. II (Columbia University Press, New York, NY).

[12] Campbell, John Y., Inspecting the mechanism: An analytical approach to the stochastic growth model, Journal of Monetary Economics 33, 463-506.

[13] Canova, Fabio, 1991, The sources of financial crises: Pre and post Fed evidence, International Economic Review 32, 689-713. 
[14] Carlstrom, Charles T. and Timothy S. Fuerst, 1996, Interest rate rules for seasonal and business cycles, Economic Commentary(July), Federal Reserve Bank of Cleveland.

[15] Carlstrom, Charles T. and Timothy S. Fuerst, 1995, Interest rate rules vs. money growth rules: A welfare comparison in a cash-in-advance economy, Journal of Monetary Economics $36,247-267$.

[16] Chari, V.V., Lawrence J. Christiano, and Martin Eichenbaum, 1994, Inside money, outside money and short term interest rates, Manuscript.

[17] Chatterjee, Satyajit, 1993, On the desirability of a seasonal monetary policy, Manuscript, Federal Reserve Bank of Philadelphia.

[18] Chatterjee, S. and B. Ravikumar, 1992, A neoclassical model of seasonal fluctuations, Journal of Monetary Economics 29, 59-86.

[19] Christiano, Lawrence J., 1988, Why does inventory investment fluctuate so much?, Journal of Monetary Economics 21, 247-280.

[20] Christiano, Lawrence J. and Martin Eichenbaum, 1992, Current real-business-cycle theories and aggregate labor market fluctuations, American Economic Review 82, 430-450.

[21] Christiano, Lawrence J. and Richard M. Todd, 1995, The seasons: Do they matter for business cycle analysis? Manuscript, Federal Bank of Minneapolis.

[22] Constantinides, George M., 1990, Habit formation: A resolution of the equity premium puzzle, Journal of Political Economy 98, 519-543

[23] Cooley, Thomas F. and Gary D. Hansen, 1995, Money and the real business cycle, in: Thomas F. Cooley, ed., Frontiers of business cycle research (Princeton University Press, Princeton, NJ).

[24] Cooley, Thomas F. and Gary D. Hansen, 1989, The inflation tax in a real business cycle model, American Economic Review 79, 733-748.

[25] Dunn, Kenneth B. and Kenneth J. Singleton, 1986, Modeling the term structure of interest rates under non-separable utility and durability of goods, Journal of Financial Economics 17, 27-55. 
[26] Eichenbaum, Martin and Lars Peter Hansen, 1990, Estimating models with intertemporal substitution using aggregate time series data, Journal of Business and Economic Statistics 8, 53-69.

[27] Eichenbaum, Martin, Lars Peter Hansen, and Kenneth J. Singleton, 1988, A time series analysis of representative agent models of consumption and leisure choice under uncertainty, Quarterly Journal of Economics 103, 51-78.

[28] Friedman, Milton, 1982, Monetary policy: Theory and practice, Journal of Money, Credit, and Banking 14, 98-118.

[29] Friedman, Milton, 1969, The optimum quantity of money and other essays (Aldine, Chicago, IL).

[30] Friedman, Milton, 1959, A program for monetary stability (Fordham University Press, New York, NY).

[31] Friedman, Milton and Anna J. Schwartz, 1963, A monetary history of the United States: 1867-1960 (Princeton University Press, Princeton).

[32] Gillman, Max, 1993, The welfare cost of inflation in a cash-in-advance economy with costly credit, Journal of Monetary Economics 31, 97-115.

[33] Hamilton, James D., 1994, Time series analysis (Princeton University Press, Princeton, $\mathrm{NJ})$.

[34] Hansen, Gary D., 1991, The cyclical and secular behavior of the labor input: Comparing efficiency units and hours worked, Program in Applied Econometrics Discussion Paper Series 36, University of California, Los Angeles.

[35] Ireland, Peter N., 1996, The role of countercyclical monetary policy, Journal of Political Economy 104, 704-723.

[36] King, Robert G., Charles I. Plosser, and Sergio T. Rebelo, 1988, Production, growth and business cycles: II. New directions, Journal of Monetary Economics 21, 309-341.

[37] King, Robert G., Charles I. Plosser, and Sergio T. Rebelo, 1987, Production, growth, and business cycles: Technical appendix, Manuscript, University of Rochester. 
[38] Kydland, Finn E. and Edward C. Prescott, 1982, Time to build and aggregate fluctuations, Econometrica 50, 1345-1370.

[39] Lucas, Robert E., 1987, Models of business cycles (Basil Blackwell, New York, NY).

[40] Lucas, Robert E. and Nancy L. Stokey, 1987, Money and interest rate in a cash-inadvance economy, Econometrica 55, 491-513.

[41] Mankiw, N. Gregory, 1987, The optimal collection of seigniorage: Theory and evidence, Journal of Monetary Economics 20, 327-341.

[42] Mankiw, N. Gregory and Jeffrey A. Miron, 1991, Should the Fed smooth interest rates? The case of seasonal monetary policy, Carnegie-Rochester Conference Series on Public Policy 34, 41-70.

[43] Miron, Jeffrey A., 1996, The economics of seasonal cycles (The MIT Press, Cambridge, MA).

[44] Miron, Jeffrey A., 1986, Financial panics, the seasonality of the nominal interest rate, and the founding of the Fed, American Economic Review 76, 125-140.

[45] Newey, Whitney K. and Kenneth D. West, 1987, A simple, positive semi-definite, heteroskedasticity and autocorrelation consistent covariance matrix, Econometrica 55, 703708.

[46] Poole, William, 1970, Optimal choice of the monetary policy instrument in a simple stochastic macro model, Quarterly Journal of Economics 84, 197-216.

[47] Prescott, Edward C., 1987, A multiple means-of-payment model, in: William A. Barnett and Kenneth J. Singleton, eds., New approaches to monetary economics (Cambridge University Press, New York, NY).

[48] Prescott, Edward C., 1986, Theory ahead of business cycle measurement, Federal Reserve Bank of Minneapolis Quarterly Review 10, 9-22.

[49] Sargent, Thomas J. and Neil Wallace, 1982, The real-bills doctrine versus the quantity theory: A reconsideration, Journal of Political Economy 90, 1212-1236. 
[50] Sargent, Thomas J. and Neil Wallace, 1975, Rational expectations, the optimal monetary instrument, and the optimal money supply rule, Journal of Political Economy 83, 241-254.

[51] Singleton, Kenneth J., 1988, Econometric issues in the analysis of equilibrium business cycle models, Journal of Monetary Economics 21, 361-386.

[52] Schreft, Stacey L., 1992, Transactions cost and the use of cash and credit, Economic Theory 2, 283-296.

[53] Sims, Christopher A., 1980, Macroeconomics and reality, Econometrica 48, 1-48.

[54] Sims, Christopher A., 1974, Seasonality in regession, Journal of the American Statistical Association 69, 618-626.

[55] Todd, Richard M., 1990, Periodic linear-quadratic methods for modeling seasonality, Journal of Economic Dynamics and Control 14, 763-795.

[56] Woodford, Michael, 1990, The optimum quantity of money, in: B. Friedman and F. Hahn, eds., Handbook of monetary economics, Vol. 2 (North-Holland, Amsterdam). 


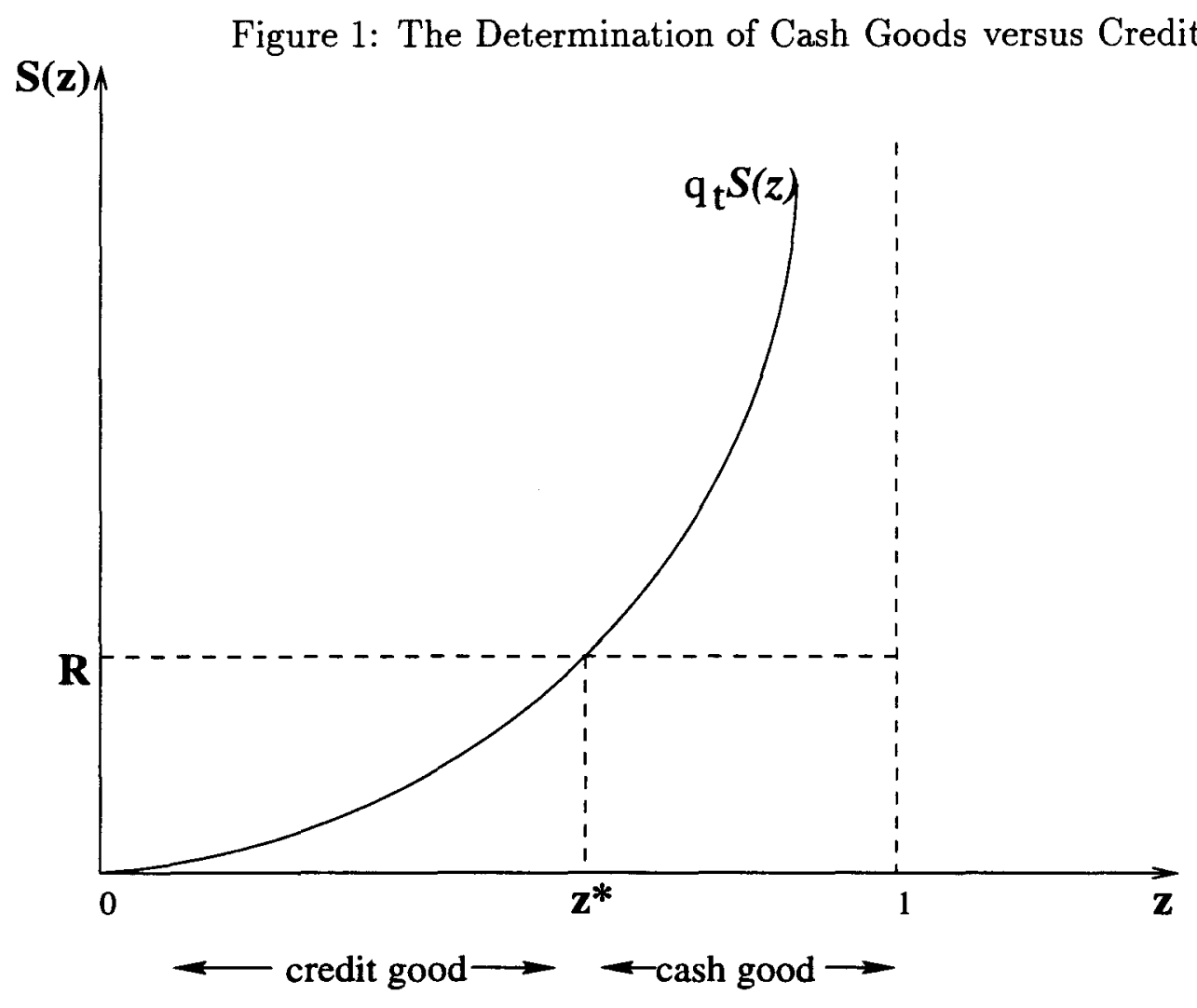

Figure 2: Real GNP(in 1967 dollars): Before and After Seasonal Adjustment

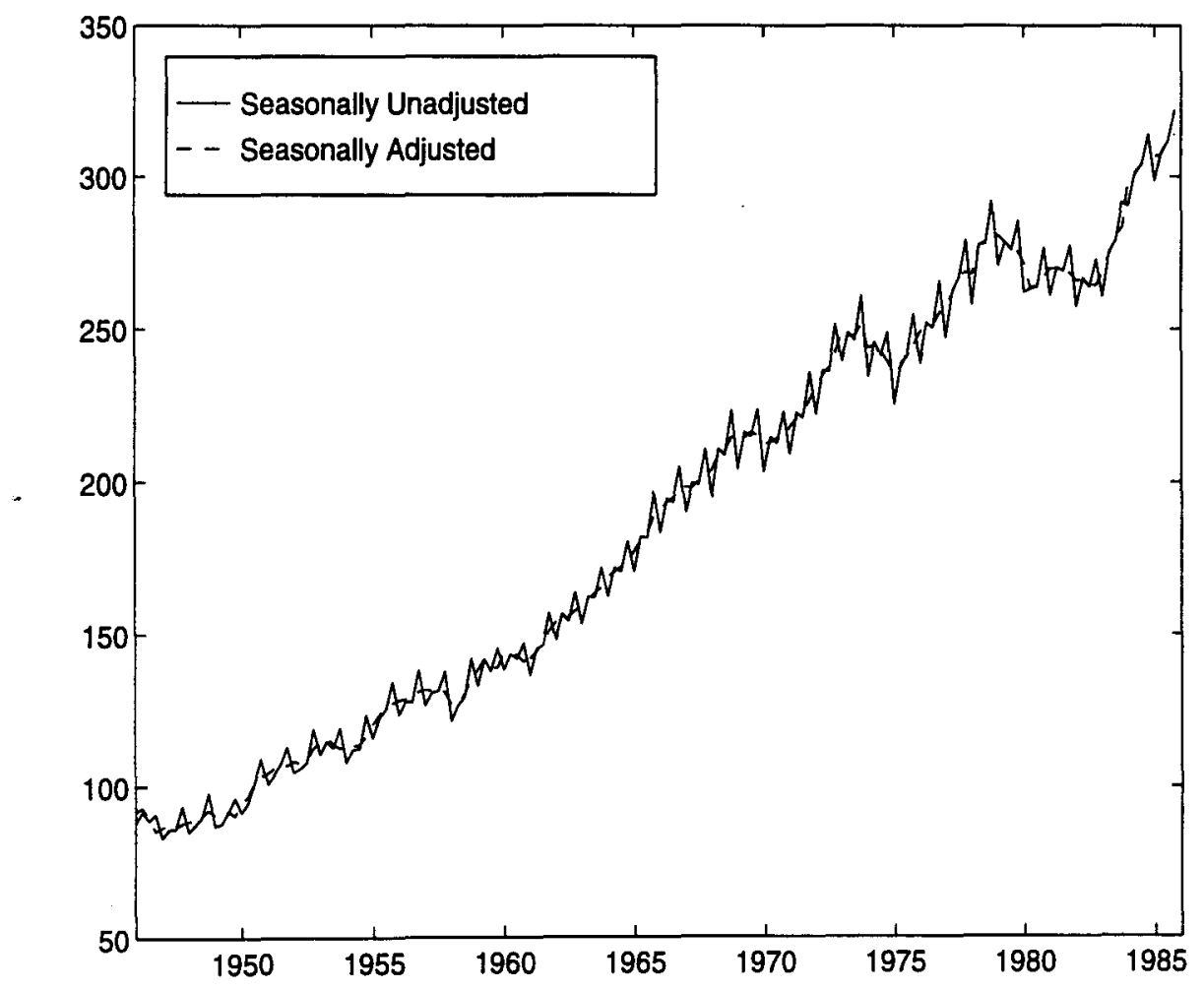


Figure 3: Nominal Interest Rate(commercial paper rate) Seasonals

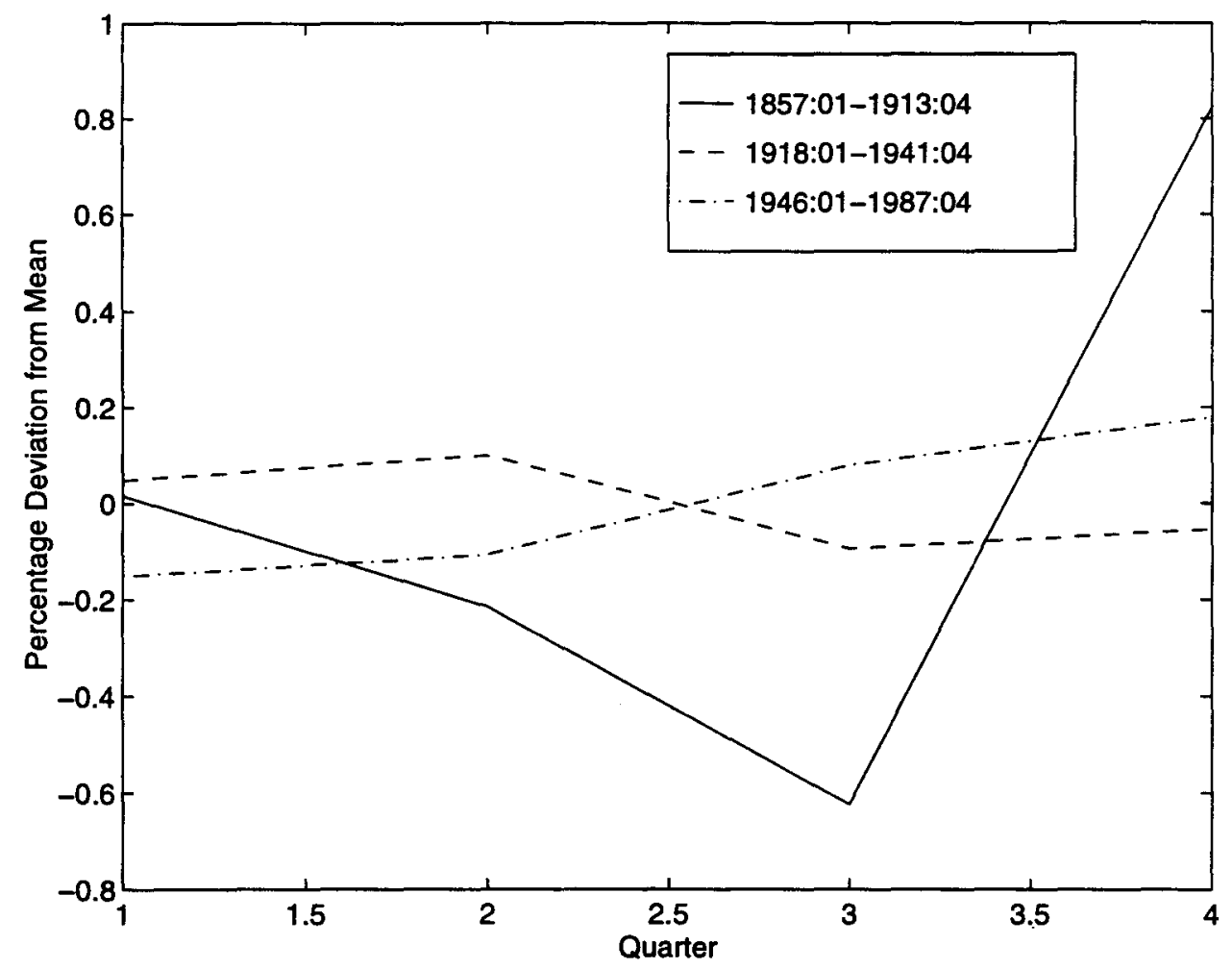

Figure 4: Commercial Paper Rate: 1857:01-1987:04, nsa

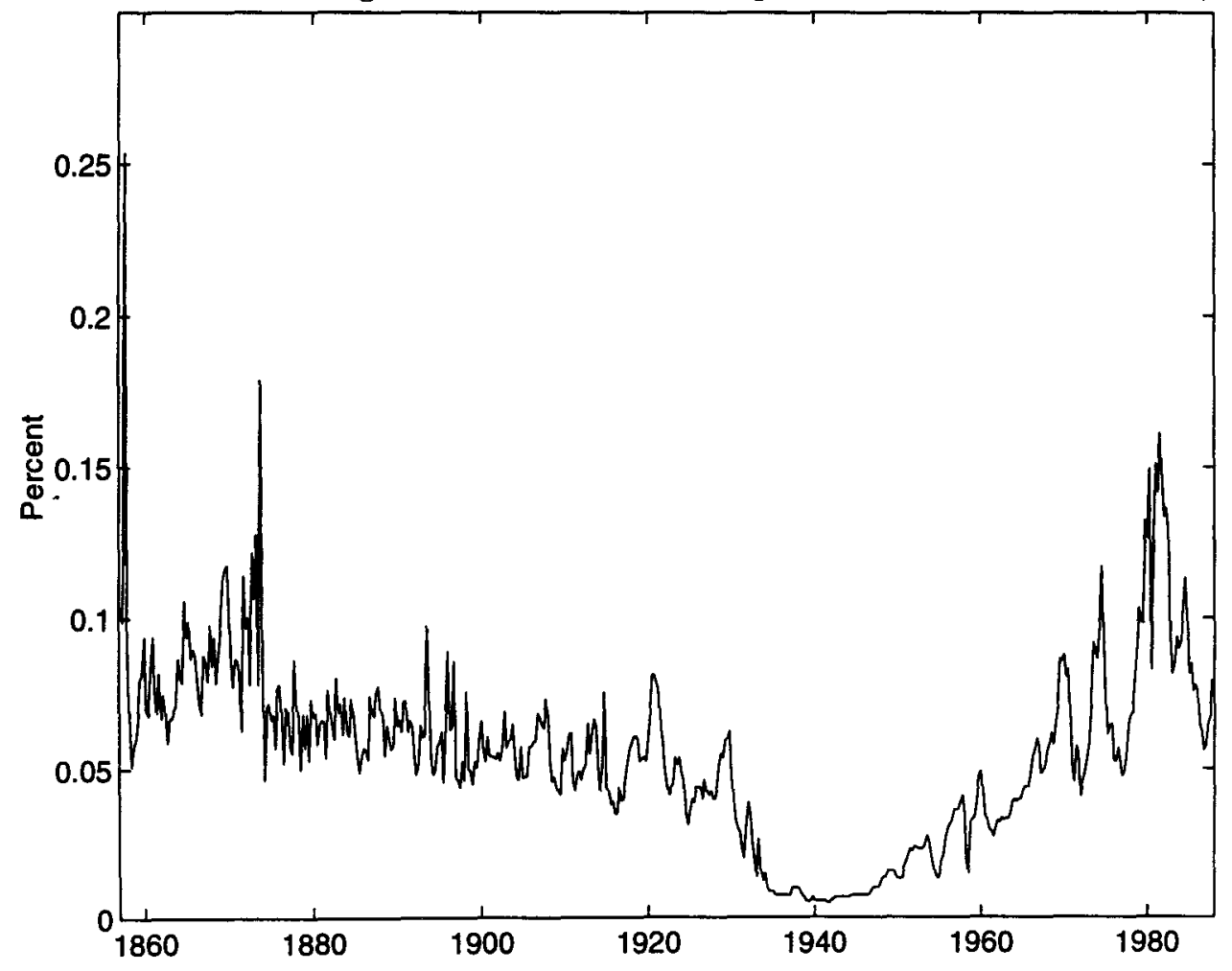


Figure 5: Seasonal Patterns: Model Versus Data
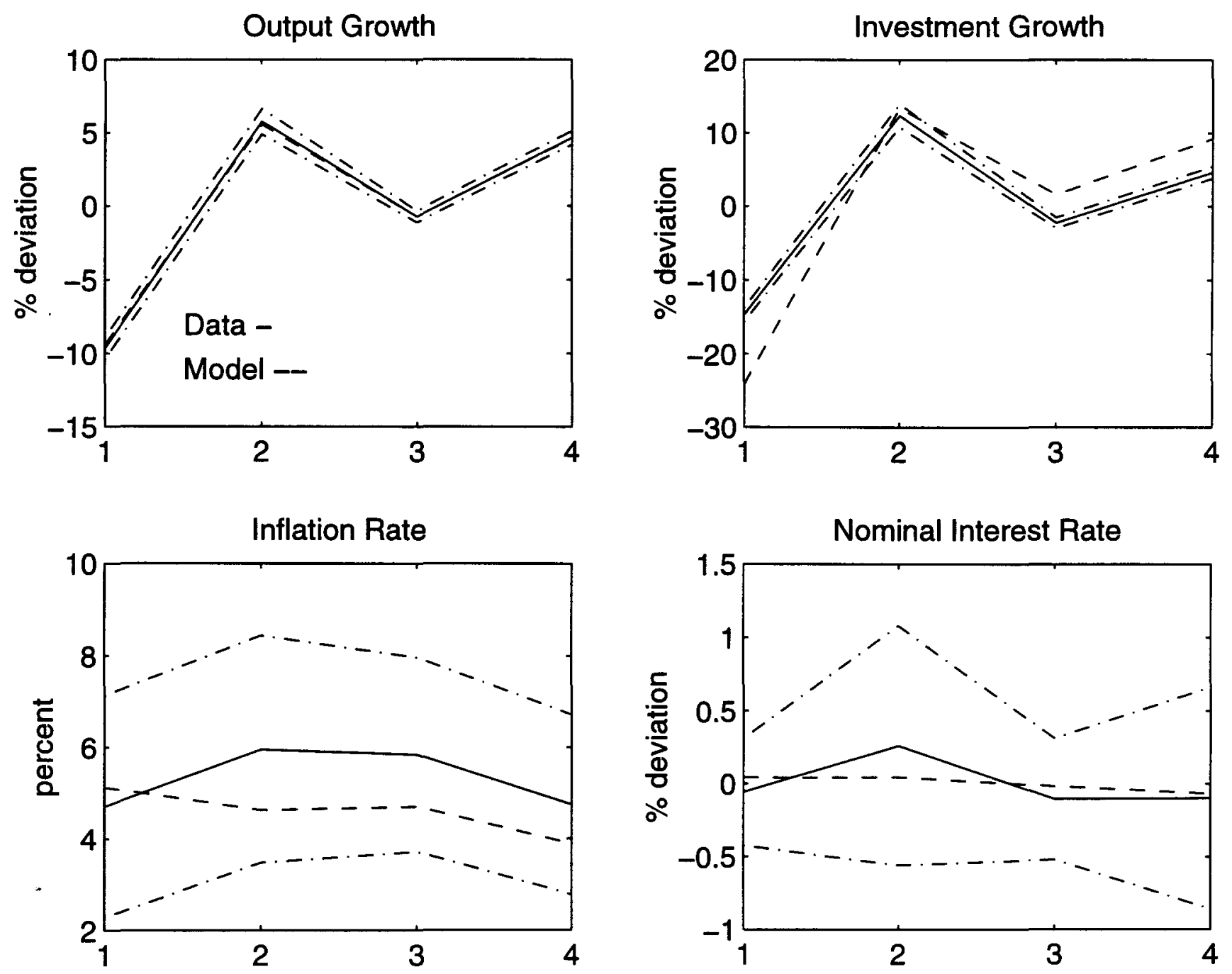
Figure 6: Seasonal Patterns for All Variables: Model versus Data
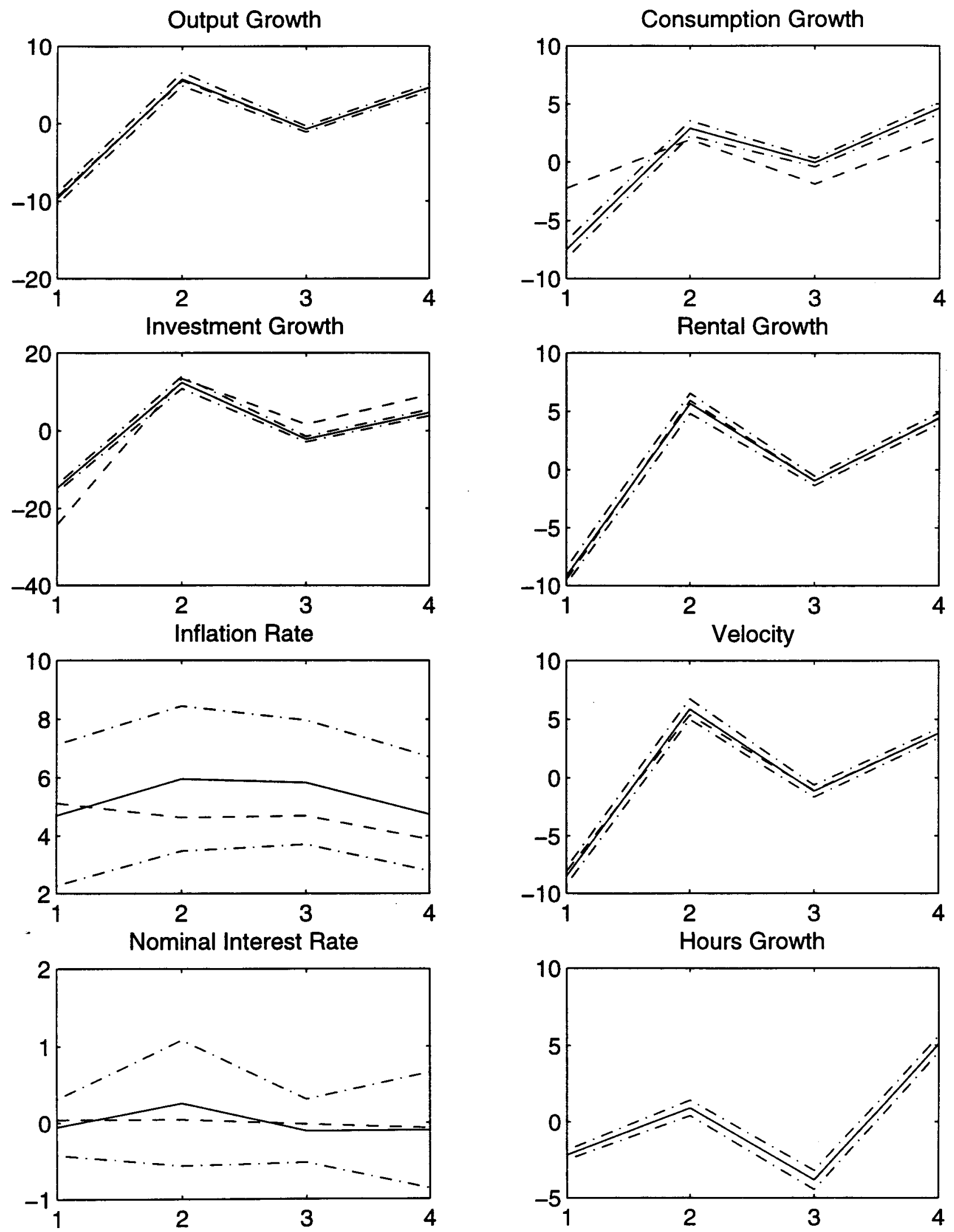
Table 1: Parameter Choice

\begin{tabular}{||c|c|c|c|c|c|r||}
\hline$\beta$ & $\delta$ & $\eta$ & $\psi$ & $\pi$ & $T$ & $\alpha$ \\
\hline $1.03^{(-0.25)}$ & 0.025 & 1 & 0.2 & 0.65 & 1369 & 0.41 \\
\hline
\end{tabular}

$$
\begin{aligned}
\left(\begin{array}{l}
\theta_{1} \\
\theta_{2} \\
\theta_{3} \\
\theta_{4}
\end{array}\right)= & \left(\begin{array}{l}
2.1762 \\
2.2711 \\
2.3760 \\
2.3168
\end{array}\right),\left(\begin{array}{l}
\lambda_{1} \\
\lambda_{2} \\
\lambda_{3} \\
\lambda_{4}
\end{array}\right)=\left(\begin{array}{l}
-0.1361 \\
0.0932 \\
0.0304 \\
0.0322
\end{array}\right),\left(\begin{array}{l}
q_{1} \\
q_{2} \\
q_{3} \\
q_{4}
\end{array}\right)=\left(\begin{array}{l}
0.0186 \\
0.0184 \\
0.0183 \\
0.0175
\end{array}\right) . \\
& \left(\begin{array}{lll}
\rho_{\lambda \lambda} & \rho_{\lambda q} & \rho_{\lambda g} \\
\rho_{q \lambda} & \rho_{q q} & \rho_{q g} \\
\rho_{g \lambda} & \rho_{g q} & \rho_{g g}
\end{array}\right)=\left(\begin{array}{ccc}
-0.2409 & 0 & 0 \\
0 & 0.7953 & 0 \\
0 & 0 & 0.5659
\end{array}\right)^{a} \\
& \left(\begin{array}{lll}
\sigma_{\lambda} & r_{\lambda q} & r_{\lambda g} \\
r_{q \lambda} & \sigma_{q} & r_{q g} \\
r_{g \lambda} & r_{g q} & \sigma_{g}
\end{array}\right)=\left(\begin{array}{ccc}
0.0226 & 0.1865 & 0.1324 \\
0.1865 & 0.0040 & 0.2584 \\
0.1324 & 0.2584 & 0.0054
\end{array}\right)^{a}
\end{aligned}
$$

${ }^{a}$ where $\sigma_{x}$ is the standard error of variable $x$, and $r_{x y}$ is the correlation coefficient of variables $x$ and $y$. 
Table 2: Seasonal Growth Rates, Data versus Model

\begin{tabular}{||c|c|c|c|c||c|c|c|c||}
\hline \hline & \multicolumn{5}{|c||}{ U.S. Data $^{a}$} & \multicolumn{5}{c||}{ Model } \\
\hline Variables & $Q_{1}$ & $Q_{2}$ & $Q_{3}$ & $Q_{4}$ & $Q_{1}$ & $Q_{2}$ & $Q_{3}$ & $Q_{4}$ \\
\hline Output & -9.66 & 5.75 & -0.74 & 4.65 & -9.41 & 5.56 & -0.75 & 4.60 \\
& $(0.36)$ & $(0.43)$ & $(0.20)$ & $(0.23)$ & & & & \\
\hline Consumption & -7.50 & 2.90 & -0.06 & 4.66 & -2.25 & 1.94 & -1.90 & 2.21 \\
& $(0.38)$ & $(0.32)$ & $(0.18)$ & $(0.25)$ & & & & \\
\hline Investment & -14.75 & 12.36 & -2.23 & 4.63 & -24.22 & 13.38 & 1.60 & 9.24 \\
& $(0.47)$ & $(0.79)$ & $(0.36)$ & $(0.40)$ & & & & \\
\hline Capital & -0.26 & 0.08 & 0.02 & 0.16 & -0.38 & -0.00 & 0.05 & 0.34 \\
& $(0.02)$ & $(0.02)$ & $(0.01)$ & $(0.02)$ & & & & \\
\hline Labor & -2.18 & 0.91 & -3.82 & 5.08 & -2.18 & 0.91 & -3.82 & 5.08 \\
Hours & $(0.16)$ & $(0.26)$ & $(0.31)$ & $(0.26)$ & & & & \\
\hline Average & -7.48 & 4.83 & 3.08 & -0.44 & -7.23 & 4.64 & 3.08 & -0.48 \\
Productivity & $(0.42)$ & $(0.40)$ & $(0.28)$ & $(0.39)$ & & & & \\
\hline Capital & -0.34 & 0.20 & -0.03 & 0.17 & -0.37 & 0.22 & -0.03 & 0.18 \\
Rental Rate & $(0.02)$ & $(0.02)$ & $(0.01)$ & $(0.01)$ & & & & \\
\hline Inflation & 4.70 & 5.96 & 5.83 & 4.75 & 5.12 & 4.63 & 4.69 & 3.89 \\
Rate & $(1.21)$ & $(1.24)$ & $(1.06)$ & $(0.99)$ & & & & \\
\hline Nominal & -0.06 & 0.26 & -0.11 & -0.10 & 0.04 & 0.04 & -0.02 & -0.07 \\
Interest Rate & $(0.18)$ & $(0.41)$ & $(0.21)$ & $(0.38)$ & & & & \\
\hline Velocity & -8.51 & 5.87 & -1.15 & 3.79 & -8.08 & 5.37 & -1.09 & 3.80 \\
& $(0.37)$ & $(0.44)$ & $(0.26)$ & $(0.21)$ & & & & \\
\hline \hline
\end{tabular}

${ }^{a}$ All variables except for the capital rental rate and nominal interest rate are logged before taking the first difference. The reported growth rate numbers are percentage deviations from the (nonseasonal) mean growth rate. The inflation rate is the annualized level, and hence not differenced. The seasonal growth rates are calculated by regressing each variable on four seasonal dummies, and the standard errors are computed using the Newey-West(1987) weighting matrix with 12 lags. 
Table 3: Selected Business Cycle Statistics

\begin{tabular}{||c|c|c|c|c||}
\hline \hline & \multicolumn{4}{|c||}{ Seasonally Adjusted Series } \\
\hline \hline & \multicolumn{2}{|c|}{ Model } & \multicolumn{2}{|c||}{ Data $^{b}$} \\
\hline$X$ & $\sigma_{x} / \sigma_{y}{ }^{c}$ & $\operatorname{Corr}(\mathrm{X}, \mathrm{Y})^{d}$ & $\sigma_{x} / \sigma_{y}$ & $\operatorname{Corr}(\mathrm{X}, \mathrm{Y})$ \\
\hline $\mathrm{Y}$ & 1.87 & 1.00 & 1.53 & 1.00 \\
\hline $\mathrm{C}$ & 0.81 & 0.90 & 0.76 & 0.84 \\
\hline $\mathrm{I}$ & 1.76 & 0.90 & 2.04 & 0.92 \\
\hline $\mathrm{K}$ & 0.10 & 0.29 & 0.18 & 0.14 \\
\hline $\mathrm{H}$ & 0.47 & 0.98 & 0.89 & 0.26 \\
\hline$R^{k}$ & 0.04 & 0.99 & 0.09 & 0.95 \\
\hline$\pi$ & 0.02 & 0.30 & 0.31 & 0.01 \\
\hline $\mathrm{P}$ & 0.72 & -0.42 & 0.58 & -0.53 \\
\hline $\mathrm{R}$ & 0.01 & 0.77 & 0.15 & 0.28 \\
\hline $\mathrm{V}$ & 0.79 & 0.83 & 0.92 & 0.77 \\
\hline
\end{tabular}

${ }^{a}$ The seasonal adjustment is made by removing the seasonal dummies.

${ }^{b}$ The data are seasonally unadjusted and are drawn from Barsky and Miron (1989).

${ }^{c}$ The first element in this column is the standard deviation of output, in percentage term. The rest are the standard deviations of variable $X$ relative to that of the output.

${ }^{d}$ This column contains contemporaneous correlations of variable $X$ with output. 
Table 4: Welfare Comparison: seasonal steady state

\begin{tabular}{||c|c|c|c||}
\hline \hline & Observed Policy & R-rule & M-rule \\
\hline Percentage $^{a}$ & 0.6369 & 0.4841 & 0.6377 \\
\hline Sbillion & 29.86 & 22.69 & 29.89 \\
\hline Seigniorage $^{b}$ & 0.35 & 0.35 & 0.35 \\
\hline \hline
\end{tabular}

Table 5: Welfare Comparison: dynamic transition path

\begin{tabular}{||c|c|c|c||}
\hline \hline & Observed Policy & R-rule & M-rule \\
\hline Percentage & 0.9541 & 1.2006 & 1.4460 \\
\hline Sbillion & 44.72 & 56.28 & 67.78 \\
\hline Seigniorage & 0.35 & 0.35 & 0.35 \\
\hline
\end{tabular}

Table 6: Impacts of policies on output and inflation volatility

\begin{tabular}{||c|c|c|c||}
\hline \hline & Observed Policy & R-rule & M-rule \\
\hline Output & 6.23 & 6.25 & 6.26 \\
Volatility & $(0.23)$ & $(0.21)$ & $(0.22)$ \\
\hline Inflation & 0.19 & 0.20 & 0.19 \\
Volatility & $(0.005)$ & $(0.005)$ & $(0.005)$ \\
\hline
\end{tabular}

${ }^{a}$ The percentage loss in consumption for each policy as compared to the economy under Friedman's rule.

${ }^{b}$ The ratio of seigniorage revenue to total output, in percentage terms. 